\author{
B. Onghena, J. Jacobs, L. Van Meervelt, K. Binnemans \\ Dalton Transactions 43, 11566-11578 (2014)
}

Cite this: DOI: 10.1039/c0xx00000x

FULL PAPER

\title{
Homogeneous liquid-liquid extraction of neodymium(III) by choline hexafluoroacetylacetonate in the ionic liquid choline bis(trifluoromethylsulfonyl)imide
}

\author{
Bieke Onghena, ${ }^{a}$ Jeroen Jacobs, ${ }^{a}$ Luc Van Meervelt ${ }^{a}$ and Koen Binnemans ${ }^{a *}$ \\ 5 Received (in $X X X, X X X)$ Xth $X X X X X X X X X 20 X X$, Accepted Xth XXXXXXXXX 20XX \\ DOI: 10.1039/b000000x
}

The ionic liquid choline bis(trifluoromethylsulfonyl)imide, $[\mathrm{Chol}]\left[\mathrm{Tf}_{2} \mathrm{~N}\right]$, was used for the extraction of neodymium(III), in combination with choline hexafluoroacetylacetonate, [Chol][hfac], as the extractant. The binary mixture of [Chol] $\left[\mathrm{Tf}_{2} \mathrm{~N}\right]$ and water shows temperature-dependent phase behavior, with an 10 upper critical solution temperature of $72{ }^{\circ} \mathrm{C}$. A novel extraction technique, homogeneous liquid-liquid extraction (HLLE), was applied to this solvent system. HLLE is based on the use of thermomorphic solvent mixtures and has the advantage of forming a homogeneous phase during mixing. Extraction is not kinetically hindered by an interface and the extraction equilibrium is reached faster than in the case of heterogeneous mixing in conventional solvent extraction. Several extraction parameters were studied for

15 the extraction of neodymium(III) with [Chol][hfac]: temperature, $\mathrm{pH}$, extractant concentration and loading of the ionic liquid phase. A speciation study was performed to determine the stoichiometry of the extracted neodymium(III) complex and a plausible extraction mechanism is proposed. Neodymium is extracted as a tetrakis hexafluoroacetylacetonate complex with one choline cation as counter ion. The crystal structure of the extracted complex showed the presence of a coordination bond between the 20 choline counter ion and the neodymium(III) center, resulting in a coordination number of nine. The stripping of the loaded neodymium and the influence of acid and extractant concentrations on the phase behavior of the $[\mathrm{Chol}]\left[\mathrm{Tf}_{2} \mathrm{~N}\right]-\mathrm{H}_{2} \mathrm{O}$ system were investigated.

\section{Introduction}

Liquid-liquid extraction or solvent extraction is widely used in 25 hydrometallurgy and is applied to the separation and processing of a wide range of metals, e.g. rare earths, hafnium-zirconium, niobium-tantalum and nickel-cobalt. ${ }^{1-3}$ Solvent extraction is based on the preferential distribution of a solute between two immiscible phases, an aqueous phase and an organic phase, that 30 are in contact with each other. The organic phase usually consists of a molecular solvent such as kerosene or toluene. Metal ions in the aqueous solution are generally hydrated and prefer to stay in the aqueous phase during solvent extraction because of the low solubility of the hydrated metal ion in the organic phase. 35 Therefore, an extractant is added to the organic phase, which will coordinate to the metal ion to form a more hydrophobic and extractable complex. Extractants can be termed acidic, basic (anion exchange) or solvating, depending on the type of complex that is formed. ${ }^{1}$ Solvent extraction has the advantage that it can be 40 implemented in a continuous mode and it is suitable for the processing of high metal feed concentrations. ${ }^{3}$ Ionic liquids are intensively studied as an alternative organic solvent for solvent extraction. ${ }^{4-6}$ Ionic liquids (ILs) are solvents that consist entirely of ions. ${ }^{7-14}$ Properties such as low volatility, low flammability, 45 wide liquidus range, good chemical stability and adjustable miscibility and polarity, make ionic liquids interesting replacements for the currently used noxious volatile organic solvents (VOCs). The specific properties of an ionic liquid depend both on the structure of the cation and the anion. Different

${ }_{50}$ cation-anion combinations result in different properties. Thus, the structure can be tuned according to the application. Ionic liquids are often highly viscous and this hampers their use in solvent extraction. ${ }^{15-18}$ In a stirred two-phase mixture during solvent extraction, two stagnant films are formed near the interface, one 55 at each side, in which movement of solute solely occurs via diffusion. The thickness of these films is correlated to the viscosity of the liquid, i.e. a higher viscosity results in a thicker film. ${ }^{1}$ Since diffusion of the solute is also slower when the viscosity is higher, a higher viscosity slows down the extraction ${ }_{60}$ kinetics in two ways. Thus, longer stirring times are required for highly viscous solvent mixtures to reach equilibrium. Moreover, mixing of highly viscous ionic liquids requires a large energy input. 


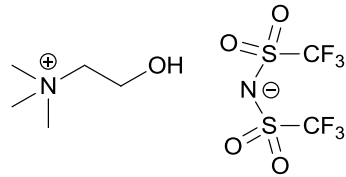

(a)

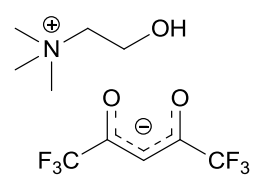

(b)
Fig. 1 Chemical structure of (a) $[\mathrm{Chol}]\left[\mathrm{Tf}_{2} \mathrm{~N}\right]$ and (b) [Chol][hfac].

In our previous work, homogeneous liquid-liquid extraction (HLLE) was introduced as an alternative technique to circumvent 5 the issue of the high viscosity of ionic liquids. ${ }^{19,20}$ It is a novel extraction technique that makes use of ionic liquid systems with thermomorphic behavior, i.e. with a temperature-dependent phase behavior and mutual solubility. ${ }^{21-26}$ In an HLLE process, an aqueous feed solution containing the metal to be extracted is 10 mixed with a thermomorphic ionic liquid and heated above the upper critical solution temperature (UCST). At this temperature, the organic phase is completely miscible with water and a homogeneous solution is obtained (homogeneous stage). Complex formation can now occur over the entire volume of the 15 solution and is no longer hindered by the interface. The speed of extraction only depends on the kinetics of the chemical reactions and extraction equilibrium will be reached faster. Upon cooling, phase separation occurs and the metal complex is extracted to the organic phase (settling stage). HLLE was first described by 20 Murata et al. for the extraction of iron(III) thenoyltrifluoroacetonate in propylene carbonate. ${ }^{27}$ In the following decades, HLLE has been mainly applied to the extraction and pre-concentration of metals for analytical purposes, extraction of organic compounds and extraction of 25 biological material. ${ }^{28-36}$ Examples of hydrometallurgical applications, however, are scarce and make use of molecular solvents only. ${ }^{37-41}$ To the best of our knowledge, HLLE has not yet been applied to hydrometallurgical applications with ionic liquids, besides the previous work by our group. ${ }^{19,20}$

30 In this paper, the potential of the ionic liquid choline bis(trifluoromethylsulfonyl)imide, [Chol] $\left[\mathrm{Tf}_{2} \mathrm{~N}\right]$, for use in HLLE of neodymium(III) is described (Fig. 1). ${ }^{26,42,43}$ Neodymium is one of the most critical rare earths and is highly demanded for use in permanent magnets, so that efficient recovery methods for this 35 element are being developed by several research groups. ${ }^{44-55}$ $[\mathrm{Chol}]\left[\mathrm{Tf}_{2} \mathrm{~N}\right]$ has been shown to exhibit thermomorphic behavior in water, with an UCST of $72{ }^{\circ} \mathrm{C} .{ }^{26}$ No specific chelating functions are present in the structure of $[\mathrm{Chol}]\left[\mathrm{Tf}_{2} \mathrm{~N}\right]$, an extractant was added. Only polar extractants could be used in 40 combination with $[\mathrm{Chol}]\left[\mathrm{Tf}_{2} \mathrm{~N}\right]$, since this ionic liquid is quite polar and non-polar extractants have a poor solubility in this ionic liquid. Moreover, the complex formed between $\mathrm{Nd}(\mathrm{III})$ and the extractant upon extraction should have a higher affinity for the ionic liquid phase than for the aqueous phase. As the $\beta$-diketone 45 hexafluoroacetylacetone meets these requirements, it was used as extractant. The ionic liquid [Chol][hfac] was preferred instead of molecular hexafluoroacetylacetone (Hhfac) since the ionic liquid is much less volatile than Hhfac. ${ }^{56}$ Moreover, the extractant moiety is already present in its deprotonated form, making it 50 immediately available for coordination and no $\mathrm{pH}$ adjustments have to be made. In principle, hexafluoroacetylacetone ionic liquids with cations other than $\mathrm{Chol}^{+}$could also be used, such as 1-butyl-3-methylimidazolium or tetrabutylphosphonium. ${ }^{56,57}$
However, the composition of the extraction system was kept as 55 simple as possible by using the same $\mathrm{Chol}^{+}$cation for both extractant and diluent. $\beta$-Diketones, such as hexafluoroacetylacetone, are known for their coordination behavior with respect to lanthanide ions and are of general interest because of their luminescence properties. ${ }^{58}$ Lanthanide $\beta$ ${ }_{60}$ diketonates have also been studied for liquid-liquid extraction, e.g. in the context of the separation of fission products from spent nuclear fuel, mostly with 2-thenoyltrifluoroacetone (Htta) as a ligand. ${ }^{58-62}$

\section{Experimental}

\section{${ }_{65}$ Products}

Neodymium(III) chloride hexahydrate (99.9\%), neodymium(III) nitrate hexahydrate $(99.9 \%)$ and neodymium(III) oxide $(99.99 \%)$ were purchased from Alfa Aesar (Karlsruhe, Germany). Lithium bis(trifluoromethylsulfonyl)imide (99\%) was obtained from 70 IoLiTec (Heilbronn, Germany). Hexafluoroacetylacetone (98\%) was obtained from ABCR GmbH (Karlsruhe, Germany). Choline chloride (99\%) was purchased from ACROS Organics (Geel, Belgium). Choline hydroxide (46 wt $\%$ in water), sodium chloride (> 98\%), hydrogen bromide (48 wt $\%$ ) and silver nitrate $(>99.8 \%$ ) 75 were obtained from Sigma-Aldrich (Diegem, Belgium). $\mathrm{HNO}_{3}$ (65\%) was obtained from Chem-Lab (Zedelgem, Belgium) and absolute ethanol from VWR (Leuven, Belgium). A $1000 \mathrm{mg} \cdot \mathrm{L}^{-1}$ dysprosium ICP standard was purchased from Merck (Overijse, Belgium). The silicone solution in isopropanol was obtained from ${ }_{80}$ SERVA Electrophoresis GmbH (Heidelberg, Germany).

\section{Equipment}

${ }^{1} \mathrm{H}$ and ${ }^{13} \mathrm{C}$ NMR spectra were recorded in $\mathrm{D}_{2} \mathrm{O}$ on a Bruker Avance 300 spectrometer, operating at $300 \mathrm{MHz}$ for ${ }^{1} \mathrm{H}$ and 75 $\mathrm{MHz}$ for ${ }^{13} \mathrm{C}$. ${ }^{19} \mathrm{~F}$ NMR spectra were recorded on a Bruker ${ }_{85}$ Avance II+ $600 \mathrm{MHz}$ spectrometer with a SCF F-H-D-05 probe (Bruker Biospin) at a frequency of $565 \mathrm{MHz}$. The temperature was controlled using a Bruker BCU 05 temperature controller, with a thermocouple type T. A $5 \mathrm{~mL}$ pycnometer was used to determine densities. FTIR spectra were recorded on a Bruker ${ }_{90}$ Vertex 70 spectrometer (Bruker Optics). Both solid and liquid samples were examined directly without further sample preparation using a Platinum ATR single reflection diamond attenuated total reflection (ATR) accessory. Analysis was performed with OPUS software. Carbon, hydrogen and nitrogen ${ }_{95}$ content were determined using a CE Instruments EA-1110 element analyzer. Water content was measured with a MettlerToledo DL39 coulometric Karl Fischer titrator. Extraction experiments were performed in a TMS-200 thermoshaker (Nemus Life). A Bruker Picofox S2 total reflection X-ray 100 fluorescence (TXRF) spectrometer was used to determine the metal concentrations in both aqueous and organic (ionic liquid) phase and the chloride content of the synthesized [Chol] $\left[\mathrm{Tf}_{2} \mathrm{~N}\right]$. Extraction mixtures were centrifuged using a Heraeus Labofuge 200. X-ray intensity data were collected at $100 \mathrm{~K}$ on an Agilent 105 Supernova diffractometer, equipped with an Atlas CCD detector, using Mo $K \alpha$ radiation $(\lambda=0.71073 \AA)$. The images were interpreted and integrated with the CrysAlisPro software from Agilent Technologies. Using Olex2, the structure was solved with the SHELXS structure solution program using Direct Methods 
and refined with the SHELXL refinement package using fullmatrix least squares minimization on $\mathrm{F}^{2}{ }^{63-65}$

\section{Synthesis of choline bis(trifluoromethylsulfonyl)imide}

Choline bis(trifluoromethylsulfonyl)imide ([Chol][Tf $\left.{ }_{2} \mathrm{~N}\right]$ ) was 5 prepared following a literature procedure. ${ }^{25}$ Choline chloride $(60.085 \mathrm{~g}, 0.430 \mathrm{~mol})$ was mixed with an equimolar amount of lithium bis(trifluoromethylsulfonyl)imide (123.556 g, $0.430 \mathrm{~mol})$ in $50 \mathrm{~mL}$ of distilled water. The mixture was stirred for one hour at room temperature. The ionic liquid phase-separated from the 10 aqueous phase and was washed with small amounts of ice-cold water in order to remove chloride impurities. The presence of chloride in the water layer after washing was tested by the addition of a small aliquot of a concentrated silver nitrate solution to the washing solution. Finally, the ionic liquid was dried in 15 vacuo on a rotary evaporator $\left(60{ }^{\circ} \mathrm{C}\right)$. A white solid product was formed. Yield: $74 \%(67.225 \mathrm{~g}, 0.176 \mathrm{~mol}){ }^{1} \mathrm{H} \mathrm{NMR}(300 \mathrm{MHz}$, [D $\mathrm{D}_{6}$ DMSO, $\left.\delta\right): 5.29$ (t, 1H, OH, J = 5.0 Hz); $3.85\left(\mathrm{~m}, 2 \mathrm{H}, \mathrm{CH}_{2}\right)$; $3.41\left(\mathrm{~m}, 2 \mathrm{H}, \mathrm{CH}_{2}\right) ; 3.12\left(\mathrm{~s}, 9 \mathrm{H}, 3 \times \mathrm{CH}_{3}\right) .{ }^{13} \mathrm{C} \mathrm{NMR}(75.47 \mathrm{MHz}$, [D $\mathrm{D}_{6}$ DMSO, $\left.\delta\right): 119.63\left(\mathrm{q}, 2 \times \mathrm{CF}_{3}, \mathrm{~J}=322 \mathrm{~Hz}\right) ; 67.23\left(\mathrm{~N}-\mathrm{CH}_{2}\right)$; $2055.29\left(\mathrm{CH}_{2}\right) ; 53.34\left(3 \times \mathrm{CH}_{3}\right)$. Elemental analysis: found (\%): $\mathrm{C}$, 21.49; H, 3.86; N, 7.20\%; calc. for $\mathrm{C}_{7} \mathrm{H}_{14} \mathrm{~N}_{2} \mathrm{O}_{5} \mathrm{~F}_{6} \mathrm{~S}_{2}: \mathrm{C}, 21.88 ; \mathrm{H}$, 3.67; N, 7.29\%. Water content: $2200 \mathrm{mg} \cdot \mathrm{kg}^{-1}$. Chloride content: < $10 \mathrm{mg} \cdot \mathrm{kg}^{-1}$. Density: $1.500 \mathrm{~g} \mathrm{~cm}^{-3}\left(60{ }^{\circ} \mathrm{C}\right)$. FTIR $\left(\mathrm{cm}^{-1}\right) 1477$ $\left(\mathrm{CH}_{2}\right) ; 1348\left(\mathrm{SO}_{2}\right) ; 1181\left(\mathrm{CF}_{3}\right) ; 1138\left(\mathrm{SO}_{2}\right) ; 1050\left(\mathrm{SO}_{2}\right) ; 953$; ${ }_{25}$ 867; 791; $741\left(\mathrm{CF}_{3}\right) ; 611 ; 570\left(\mathrm{CF}_{3}\right) ; 513\left(\mathrm{CF}_{3}\right)$.

\section{Preparation of the ionic liquid phase}

As described in the literature, [Chol][hfac] is not stable at elevated temperatures and decomposition occurs fast. ${ }^{56}$ Thus, special drying techniques are required to obtain a pure and dry 30 product. However, since the extraction studies described in this paper do not require dry [Chol][hfac], but [Chol][hfac] dissolved in the ionic liquid phase, [Chol] [hfac] was prepared directly in the ionic liquid $[\mathrm{Chol}]\left[\mathrm{Tf}_{2} \mathrm{~N}\right]$. Choline hydroxide (46 wt\% solution in water) and hexafluoroacetylacetone (Hhfac) were

35 added to dry [Chol] $\left[\mathrm{Tf}_{2} \mathrm{~N}\right]$ in equimolar quantities. Water was added to this mixture to obtain a water content of $8 \mathrm{wt} \%$. A small amount of this [Chol] [hfac]-[Chol] $\left[\mathrm{Tf}_{2} \mathrm{~N}\right]$ mixture was then added to $[\mathrm{Chol}]\left[\mathrm{Tf}_{2} \mathrm{~N}\right]$ (containing $8 \mathrm{wt} \%$ of water) to obtain the organic (ionic liquid) phase of the extraction mixture. Because of its 40 hygroscopic behavior, a $[\mathrm{Chol}]\left[\mathrm{Tf}_{2} \mathrm{~N}\right]$ solution containing a certain amount of water ( $8 \mathrm{wt} \%$ in this case) was used instead of pure dry ionic liquid, in order to prevent further uncontrolled uptake of water. Moreover, water-containing $[\mathrm{Chol}]\left[\mathrm{Tf}_{2} \mathrm{~N}\right]$ is liquid, thus easier to dispense than solid [Chol] $\left[\mathrm{Tf}_{2} \mathrm{~N}\right]$.

\section{${ }_{45}$ Extraction experiments}

At a temperature of $20{ }^{\circ} \mathrm{C}, 12 \mathrm{wt} \%$ of $[\mathrm{Chol}]\left[\mathrm{Tf}_{2} \mathrm{~N}\right]$ dissolves in water and $10 \mathrm{wt} \%$ of water dissolves in $[\mathrm{Chol}]\left[\mathrm{Tf}_{2} \mathrm{~N}\right] \cdot{ }^{26}$ During a typical extraction experiment, this mutual solubility was taken into account and the ionic liquid phase and water were always 50 mixed in such proportions that two phases were obtained in a 1:1 mass ratio in the final extraction mixture after phase equilibration. A 1:1 mass ratio simplifies calculation of the distribution ratio $D$ and percentage extraction $\% E$ (see 'Results and discussion'). In order to obtain a 1:1 ratio, $1109 \mathrm{mg}$ of ionic 55 liquid phase, containing a certain amount of [Chol] $\left[\mathrm{Tf}_{2} \mathrm{~N}\right]$ extractant $\left(50 \mathrm{mmol} \cdot \mathrm{kg}^{-1}\right.$, unless otherwise specified $)$ was mixed with $891 \mathrm{mg}$ of metal feed solution (nitrate, chloride or bromide medium). The metal concentration in the aqueous feed was 15 $\mathrm{mmol} \cdot \mathrm{kg}^{-1}$ unless otherwise specified. The initial $\mathrm{Nd}(\mathrm{III})$ 60 concentration in the aqueous phase was recalculated according to the phase equilibrium to $12 \mathrm{mmol} \cdot \mathrm{kg}^{-1}$ (unless otherwise specified). The extraction mixture was heated and gently shaken in a thermoshaker at $700 \mathrm{rpm}$ and $80{ }^{\circ} \mathrm{C}$ for $3 \mathrm{~min}$ to obtain one homogeneous phase. The mixture was cooled to room 65 temperature to induce settling and two phases were again obtained. After waiting for $1 \mathrm{~h}$ to make sure settling was completed, a small sample (100 mg) was taken from the aqueous phase to determine the metal concentration in the aqueous phase with a TXRF spectrometer. A small amount $(100 \mathrm{mg})$ of 70 dysprosium nitrate ICP standard solution (1000 $\left.\mathrm{mg} \mathrm{L}^{-1}\right)$ was added to the sample as the reference for quantification and further diluted with $1 \mathrm{~mL}$ of MilliQ ${ }^{\circledR}$ water. A dysprosium standard was used because the detected dysprosium L-lines are close to those of neodymium, but there is no overlap. Thus, secondary 75 absorption by the ionic liquid matrix on the carrier has a similar influence on the radiation of dysprosium and neodymium. The prepared sample solution was homogenized and a small droplet (5 $\mu \mathrm{L}$ ) was dispensed on a quartz sample carrier. Finally, the carrier containing the sample was dried at $60^{\circ} \mathrm{C}$ for $15 \mathrm{~min}$. Prior 80 to dispensing the sample droplet, the quartz carrier was pretreated with a SERVA ${ }^{\circledR}$ silicone solution in isopropanol $(10 \mu \mathrm{L})$ in order to make the surface more hydrophobic and keep the sample droplet in the middle of the carrier.

Extraction of $\mathrm{Nd}(\mathrm{III})$ is evaluated by calculating the ${ }_{85}$ distribution ratio $D$ and percentage extraction $\% E$ by following equations:

$$
\begin{gathered}
D=\frac{[\mathrm{M}]_{\text {org }}}{[\mathrm{M}]_{\text {aq }}} \\
\% E=\frac{[\mathrm{M}]_{\text {org }}}{[\mathrm{M}]_{\text {org }}+[\mathrm{M}]_{\text {aq }}} \cdot 100 \%
\end{gathered}
$$

where $[\mathrm{M}]_{\text {org }}$ and $[\mathrm{M}]_{a q}$ are the metal ion concentration (in $90 \mathrm{~mol} \cdot \mathrm{kg}^{-1}$ ) in the organic phase and the aqueous phase, respectively. $[\mathrm{M}]_{a q}$ was measured using TXRF. Since aqueous and organic phase were present in a 1:1 mass ratio, the metal ion concentration in the organic phase was calculated as follows:

$$
[\mathrm{M}]_{\text {org }}=[\mathrm{M}]_{a q, \text { in }}-[\mathrm{M}]_{a q}
$$

95 where $[\mathrm{M}]_{a q, \text { in }}$ and $[\mathrm{M}]_{a q}$ are the initial and final (measured) metal ion concentration in the aqueous phase, respectively.

\section{Preparation of neodymium(III) bromide hydrate}

Neodymium(III) bromide hydrate was prepared by adding $\mathrm{Nd}_{2} \mathrm{O}_{3}$ (1 $\mathrm{g}, 3.0 \mathrm{mmol})$ to a $\mathrm{HBr}$ solution $(48 \%, 3.006 \mathrm{~g}, 18 \mathrm{mmol}$ ), 100 diluted in $10 \mathrm{~mL}$ of water. The mixture was stirred for $1 \mathrm{~h}$ and $\mathrm{NdBr}_{3} \cdot x \mathrm{H}_{2} \mathrm{O}$ was crystallized out of solution by drying on a rotary evaporator.

\section{Study of temperature influence on extraction}

The influence of temperature on extraction was studied using four 105 identical extraction mixtures (same procedure as above for the extraction experiments). All mixtures were heated at different temperatures $\left(30\right.$ to $80{ }^{\circ} \mathrm{C}$ ) for $2 \mathrm{~min}$. The last $5 \mathrm{~s}$ of heating, the mixtures were shaken $(600 \mathrm{rpm})$. Next, the mixtures were 
quenched in an ice bath and centrifuged (5000 rpm, $1 \mathrm{~min}$ ). The aqueous phase was isolated and its neodymium content was determined by TXRF (same procedure as above for the extraction experiments).

\section{${ }_{5}$ Stripping experiments}

Stripping experiments were performed by mixing $1.0 \mathrm{~g}$ of $[\mathrm{Chol}]\left[\mathrm{Tf}_{2} \mathrm{~N}\right]$ phase obtained after extraction of $\mathrm{Nd}(\mathrm{III})$, with 1.0 $\mathrm{g}$ of diluted $\mathrm{HNO}_{3}$ solution (concentration ranging from 0 to 2 $\mathrm{mol} \cdot \mathrm{L}^{-1}$ ). The mixtures were heated to $80{ }^{\circ} \mathrm{C}$ and shaken for 3 $10 \mathrm{~min}$ to obtain one homogeneous solution and again cooled to room temperature to induce phase separation. After $1 \mathrm{~h}$ of settling, the metal content in the aqueous and organic phase was measured with TXRF. The sample preparation of the aqueous phase proceeded according to the method described above. 15 Samples of the organic phase were prepared by adding a small amount of dysprosium standard solution $\left(1000 \mathrm{mg} \cdot \mathrm{L}^{-1}\right)$ to $100 \mathrm{mg}$ of the organic phase and diluting it with $1 \mathrm{~mL}$ of pure ethanol. Approximately $2 \mu \mathrm{L}$ of the prepared sample solution was dispensed on the quartz glass carrier.

20 Stripping was evaluated using the stripping efficiency $\% S$, which is calculated as follows:

$$
\% S=\frac{[M]_{a q, s t r}}{[M]_{a q, s t r}+[M]_{o r g, s t r}} \cdot 100 \%
$$

where $[\mathrm{M}]_{a q, s t r}$ is the metal concentration in the aqueous phase after stripping and $[\mathrm{M}]_{\text {org,str }}$ the metal concentration in the organic 25 phase after stripping.

\section{Cloud point determination}

Cloud point determinations were performed by placing a $4 \mathrm{~mL}$ vial, closed with a cap and containing the solvent mixture to be studied, in a temperature-controlled water bath. The solvent 30 mixture was heated and stirred until the mixture turned homogeneous. Next, the heating was turned off and the mixture was slowly cooled. The transparency of the mixture was monitored visually and the temperature at which the homogeneous mixture became cloudy was recorded. The 35 determination of this cloud point temperature was repeated three times to get an accurate result. The mixtures all contained 1109 $\mathrm{mg}$ of $[\mathrm{Chol}]\left[\mathrm{Tf}_{2} \mathrm{~N}\right]$ solution (water content of $8 \mathrm{wt} \%$ and a varying amount of [Chol][hfac]) and $891 \mathrm{mg}$ of water or diluted $\mathrm{HNO}_{3}$ (concentration varying between 0 and $2 \mathrm{~mol} \cdot \mathrm{L}^{-1}$ ).

\section{${ }_{40}$ Study of decomposition [Chol][hfac]}

${ }^{19} \mathrm{~F}$ NMR spectroscopy was applied to monitor the decomposition reaction of [Chol][hfac] with water. [Chol][hfac] was prepared by adding choline hydroxide (46 wt $\%$ in water) to pure hexafluoroacetylacetone. Immediately after mixing, a sample was 45 taken and diluted in deuterated methanol $\left(\mathrm{CD}_{3} \mathrm{OD}\right)$. The sample was placed inside the NMR spectrometer and heated to $80{ }^{\circ} \mathrm{C}$ using the temperature controller of the NMR device. Every $26 \mathrm{~s}$, a ${ }^{19} \mathrm{~F}$ NMR spectrum was recorded. The sample was not locked or shimmed before the start of the measurements since the ${ }_{50}$ decomposition reaction of the pure [Chol] [hfac] in water occurred fast and locking and shimming would require too much time. The spectrum reference (SR) was used because standard ${ }^{19} \mathrm{~F}$ references evaporated at $80{ }^{\circ} \mathrm{C}$ and could not be applied.

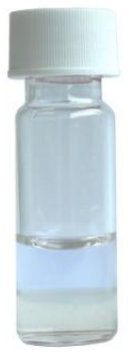

(a)

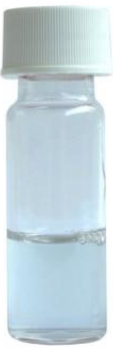

(b)

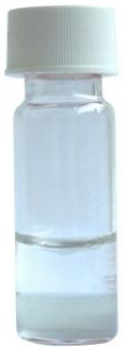

(c)
55 Fig. 2 Homogeneous liquid-liquid extraction of $\mathrm{Nd}$ (III) (purple color) from a nitrate solution with [Chol][hfac] (yellow color) dissolved in [Chol] $\left[\mathrm{Tf}_{2} \mathrm{~N}\right]$. Left: before extraction $\left(20^{\circ} \mathrm{C}\right)$, middle: during homogeneous stage $\left(80^{\circ} \mathrm{C}\right)$, right: after settling $\left(20^{\circ} \mathrm{C}\right)$. The upper phase is the aqueous phase, the lower phase in the ionic liquid phase.

\section{${ }_{60}$ Crystallography}

Single crystals of [Chol] $\left[\mathrm{Nd}(\mathrm{hfac})_{4}\right]$ suitable for X-ray diffraction were obtained by crystallization upon cooling of an extraction mixture ( $\mathrm{Nd}$ concentration in feed was $0.1 \mathrm{~mol} \cdot \mathrm{kg}^{-1}$, extractant concentration in organic phase was $144 \mathrm{mmol} \cdot \mathrm{kg}^{-1}$ ). The choline 65 ligand was modeled in two positions with an occupancy of 0.605(9):0.395(9). The second orientation binds to an extra water molecule O52 (occupancy 0.395(9)). The choline ligand and O52 were isotropically refined with DFIX restraints on both choline orientations. Non-hydrogen atoms of other parts were 70 anisotropically refined and the hydrogen atoms in the riding mode with isotropic temperature factors were fixed at 1.2 times $\mathrm{U}_{\mathrm{eq}}$ of the parent atoms (1.5 for methyl groups). The anisotropic displacement parameters of the fluorine atoms were restrained to be approximately isotropic and components of the displacement 75 parameters in the directions of the $\mathrm{C}-\mathrm{F}$ bond were restrained to be equal. CCDC 1000170 contains the supplementary crystallographic data for this paper and can be obtained free of charge via www.ccdc.cam.ac.uk/conts/retrieving.html (or from the Cambridge Crystallographic Data Centre, 12, Union Road, ${ }_{80}$ Cambridge CB2 1EZ, UK; fax: +44-1223-336033; or deposit@ccdc.cam.ac.uk).

Crystal data for [Chol] $\left[\mathrm{Nd}(\mathrm{hfac})_{4}\right]: \mathrm{C}_{25} \mathrm{H}_{17} \mathrm{~F}_{24} \mathrm{NNdO}_{9.395}, M=$ $1081.96 \mathrm{~g} \mathrm{~mol}^{-1}$, monoclinic, $\mathrm{P} 21 / \mathrm{n}$ (no. 14), $a=11.03826(19) \AA$, $b=18.5663(5) \AA, c=17.8663(3) \AA, \beta=92.0479(17), \mathrm{V}=$ ${ }_{85} 3659.18(13) \AA^{3}, T=100 \mathrm{~K}, Z=4$, $\rho_{\text {calcd }}=1.964 \mathrm{~g} \mathrm{~cm}^{-3}, \mu($ Mo K $\alpha)$ $=1.592 \mathrm{~mm}^{-1}, F(000)=2101.0$, crystal size $0.27 \times 0.22 \times 0.16$ $\mathrm{mm}^{3}, 26960$ reflections measured, 7466 unique $\left(R_{\text {int }}=0.0266\right)$ which were used in all calculations. The final $w R_{2}$ was 0.1290 (all data) and $R_{1}$ was $0.0481(>2 \sigma(\mathrm{I}))$.

\section{${ }_{90}$ Results and discussion}

\section{Variation of extraction parameters}

Homogeneous liquid-liquid extraction was carried out with the [Chol] $\left[\mathrm{Tf}_{2} \mathrm{~N}\right]-[\mathrm{Chol}][$ hfac] extraction system (Fig. 2). [Chol] $\left[\mathrm{Tf}_{2} \mathrm{~N}\right]$ shows thermomorphic behavior with an UCST of ${ }_{95} 72.1{ }^{\circ} \mathrm{C} .{ }^{26}$ Some additives to the aqueous phase of a $[\mathrm{Chol}]\left[\mathrm{Tf}_{2} \mathrm{~N}\right]-\mathrm{H}_{2} \mathrm{O}$ mixture increase the UCST, such as inorganic salts like $\mathrm{Nd}\left(\mathrm{NO}_{3}\right)_{3}$ in this case. Therefore, the extraction mixtures were heated to $80{ }^{\circ} \mathrm{C}$ to assure that a homogeneous solution is formed during the mixing stage. 


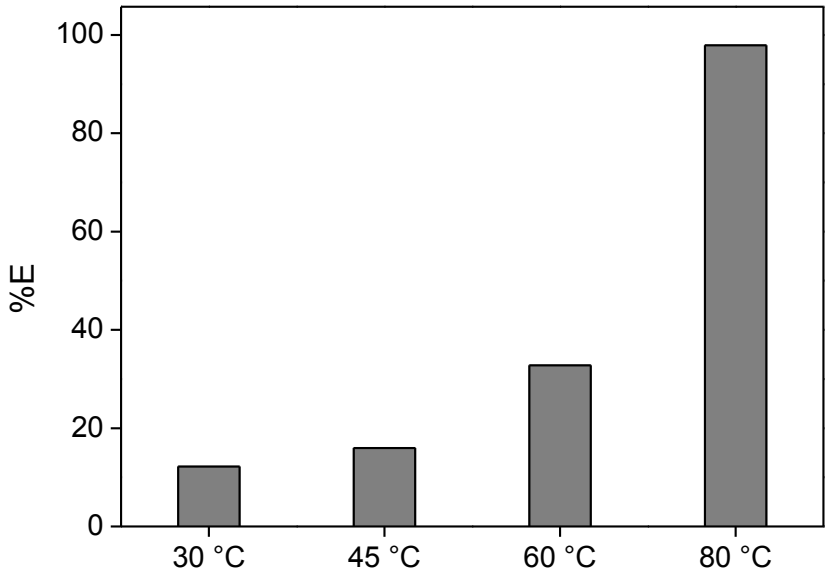

Fig. 3 Influence of temperature on $\% E$ of $\mathrm{Nd}(\mathrm{III})$ from a nitrate solution with [Chol] [hfac] $-[\mathrm{Chol}]\left[\mathrm{Tf}_{2} \mathrm{~N}\right] .50 \mathrm{mmol} \cdot \mathrm{kg}^{-1}[\mathrm{Chol}][\mathrm{hfac}]$ in organic phase, $12 \mathrm{mmol} \cdot \mathrm{kg}^{-1} \mathrm{Nd}(\mathrm{III})$ in aqueous phase.

5 For HLLE, it is in principle sufficient to just heat the extraction mixture above the UCST to obtain a homogeneous phase, without applying any agitation. However, similarly to [Hbet] $\left[\mathrm{Tf}_{2} \mathrm{~N}\right]$, diffusion of the $[\mathrm{Chol}]\left[\mathrm{Tf}_{2} \mathrm{~N}\right]$ molecules into the aqueous phase is too slow to obtain a homogeneous phase in a 10 short time scale. ${ }^{19,20}$ Thus, the mixture should be gently shaken ( 5 s) to obtain a homogeneous phase. To show the advantage of the formation of a homogeneous phase during extraction, this procedure (heating the extraction mixture to the required temperature and shaking it for $5 \mathrm{~s}$ ) was applied to the extraction 15 of $\mathrm{Nd}(\mathrm{III})$ at different temperatures between 30 and $80{ }^{\circ} \mathrm{C}$ (Fig. 3 ). To obtain the required temperature, the mixtures were heated for $2 \mathrm{~min}$. Next, they were shaken for $5 \mathrm{~s}$ and immediately quenched in an ice bath. At low temperatures $\left(30-45^{\circ} \mathrm{C}\right)$, almost no $\mathrm{Nd}(\mathrm{III})$ was extracted. At higher temperatures $\left(60^{\circ} \mathrm{C}\right)$, but still 20 below the UCST, extraction of $\mathrm{Nd}$ (III) occured to some extent, but still less than $50 \%$ of $\mathrm{Nd}(\mathrm{III})$ was extracted. The extracted amount is a little higher at $60{ }^{\circ} \mathrm{C}$ compared to $30{ }^{\circ} \mathrm{C}$, since an increase in temperature lowers the viscosity of the ionic liquid phase, thus facilitating diffusion of ions through the films near 25 the interface. Extraction at $80{ }^{\circ} \mathrm{C}$ (above the UCST) clearly showed the positive effect of the formation of a homogeneous stage. After shaking for $5 \mathrm{~s}$, a homogeneous phase was obtained and immediately, the extractable complex was formed resulting in almost $100 \%$ extraction. To obtain the same $\% E$ at 30 temperatures below the UCST, the extraction mixture had to be shaken for $2 \mathrm{~min}$ at $65^{\circ} \mathrm{C}$ and up to $10 \mathrm{~min}$ at $30{ }^{\circ} \mathrm{C}$. So, it can be concluded that HLLE can be performed on a shorter time scale compared to conventional liquid-liquid extraction and the extraction mixtures have to be shaken for a much shorter time.

35 The influence of several extraction parameters on $\% E$ was examined: the extractant concentration, $\mathrm{pH}$ and metal feed concentration. The percentage extraction increased when the amount of [Chol][hfac] extractant in the extraction mixture was raised (Fig. 4). Almost 100\% extraction was achieved with 60 $40 \mathrm{mmol} \cdot \mathrm{kg}^{-1}$ [Chol] [hfac] in the organic phase. The same extraction behavior as a function of [Chol][hfac] concentration was observed for extraction from chloride solution, meaning that the counter ion in the aqueous metal solution (being chloride or nitrate) has no influence on the extraction behavior.

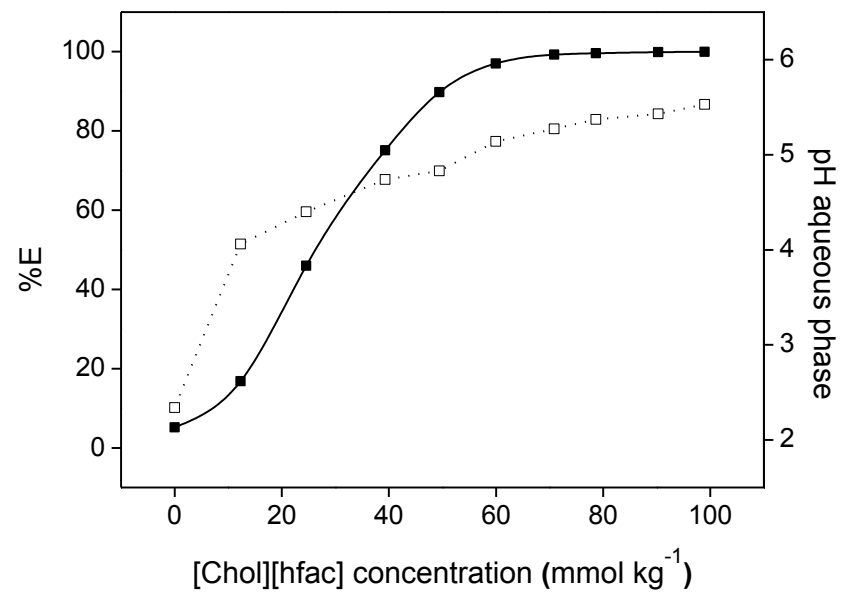

Fig $4 \% E(\mathbb{\square})$ of $\mathrm{Nd}(\mathrm{III})$ from a nitrate solution with [Chol][hfac]$[\mathrm{Chol}]\left[\mathrm{Tf}_{2} \mathrm{~N}\right]$ as a function of the [Chol] [hfac] concentration in the organic phase. $12 \mathrm{mmol} \cdot \mathrm{kg}^{-1} \mathrm{Nd}(\mathrm{III})$ and $0.01 \mathrm{M} \mathrm{HNO}_{3}$ in aqueous phase, equilibrium $\mathrm{pH}$ is indicated with.$\square$.

50 Extraction from both types of feed solution proceeded equally well. From Fig. 4, it can be seen that the $\mathrm{pH}$ increased with increasing [Chol][hfac] concentration. This can be rationalized considering the following acid dissociation equilibrium:

$$
\text { Hhfac } \rightleftarrows \text { hfac }^{-}+\mathrm{H}^{+}
$$

$55 \mathrm{HNO}_{3}$ was initially added to the extraction mixtures to keep the $\mathrm{pH}$ low enough to prevent hydrolysis of $\mathrm{Nd}(\mathrm{III})$ ions. The amount of protons $\left(\mathrm{H}^{+}\right)$present in the aqueous start solution was the same in every extraction mixture $(0.01 \mathrm{mmol})$. When $\mathrm{hfac}^{-}$is added (e.g. as [Chol][hfac]), the acid dissociation equilibrium of ${ }_{60}$ Hhfac shown in equation (5) was shifted to the left and the equilibrium proton concentration decreased, resulting in an increasing $\mathrm{pH}$ value. Hexafluoroacetylacetone (Hhfac) is an organic acid, with hfac $^{-}$as its conjugated base. The acid concentration in the aqueous phase is expected to influence the ${ }_{65}$ extraction, since part of the $\mathrm{hfac}^{-}$anions are protonated when acid is present. It was shown that at $\mathrm{pH} 5.5$ (which corresponds to an extraction mixture without extra $\mathrm{HNO}_{3}$ added to the aqueous phase), nearly all $\mathrm{Nd}(\mathrm{III})$ ions were removed from the aqueous phase (Fig. 5). No precipitation was observed, so the removal of ${ }_{70} \mathrm{Nd}$ (III) from solution was completely due to extraction to the organic phase. Moreover, it can be concluded that no nonextractable hydrolysis products were formed, since all metals are extracted and a $\% E$ of almost $100 \%$ was obtained. So, it was not necessary to add extra acid to the feed of the extraction mixture to 75 prevent hydrolysis. 


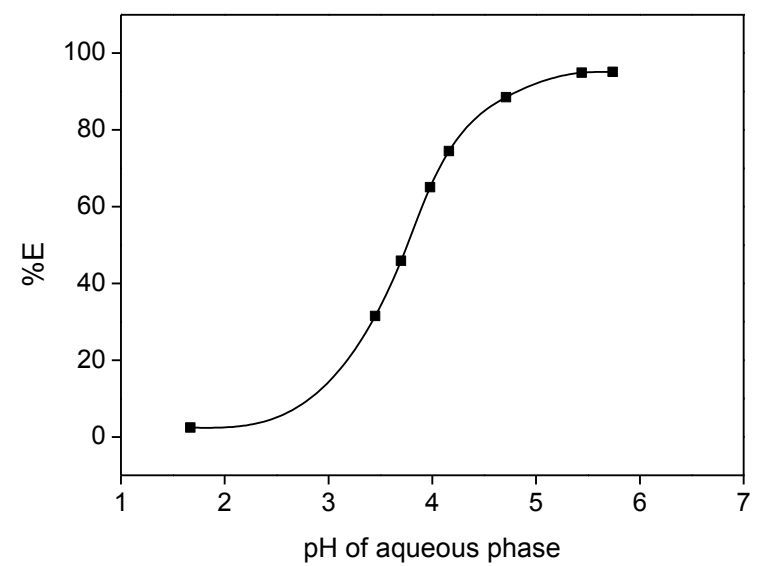

Fig. $5 \% E$ of $\mathrm{Nd}(\mathrm{III})$ from a nitrate solution with [Chol][hfac][Chol] $\left[\mathrm{Tf}_{2} \mathrm{~N}\right]$ as a function of the equilibrium $\mathrm{pH}$ of the aqueous phase at room temperature. $50 \mathrm{mmol} \cdot \mathrm{kg}^{-1}$ [Chol] [hfac] in organic phase, 12 $\mathrm{mmol} \cdot \mathrm{kg}^{-1} \mathrm{Nd}(\mathrm{III})$ and $0-0.1 \mathrm{M} \mathrm{HNO}_{3}$ in aqueous phase.

Additionally, from Fig. 5 it can be seen that by lowering the equilibrium $\mathrm{pH}$ after addition of $\mathrm{HNO}_{3}$ to the aqueous phase, the percentage extraction decreased sharply between $\mathrm{pH} 3-5$. At $\mathrm{pH}$ $<2$, extraction of $\mathrm{Nd}$ (III) is almost negligible since all [hfac] ${ }^{-}$ 10 anion are protonated and the ionic liquid [Chol][hfac] is destroyed.

The influence of the metal ion concentration in the aqueous feed on $\% E$ was also investigated, at constant $\mathrm{pH}$ and at constant extractant concentration. As expected, the percentage extraction 15 decreased with increasing metal feed concentration because the amount of extracted metal ions is always approximately constant (Fig. 6).

The extraction capacity of the system was determined by examining the maximum loading of $\mathrm{Nd}(\mathrm{III})$ in the organic phase.

20 It was shown earlier that $100 \%$ extraction could be obtained for an extractant concentration of $60 \mathrm{mmol} \cdot \mathrm{kg}^{-1}$ or higher (Fig. 4). This counts for a $\mathrm{Nd}(\mathrm{III})$ feed solution of $15 \mathrm{mmol} \cdot \mathrm{kg}^{-1}$. To increase the loading of the organic phase, the metal feed concentration and the extractant concentration were increased. ${ }_{25}$ When testing the extraction from a $100 \mathrm{mmol} \cdot \mathrm{kg}^{-1} \mathrm{Nd}(\mathrm{III})$ solution (excess), precipitation of the extractable $\mathrm{Nd}(\mathrm{III})$ complex was observed for [Chol][hfac] concentrations of more than 145 mmol $\mathrm{kg}^{-1}$. To determine how much $\mathrm{Nd}(\mathrm{III})$ can maximally be extracted with $144 \mathrm{mmol} \cdot \mathrm{kg}^{-1}$ of extractant, extraction was tested 30 from different concentrations of $\mathrm{Nd}(\mathrm{III})$ feed solution, between 10 and $100 \mathrm{mmol} \cdot \mathrm{kg}^{-1}$. As expected, the percentage extraction $\% E$ decreased with increasing $[\mathrm{Nd}]_{\mathrm{aq}, \text { in }}$ (Fig. 7), similarly as shown earlier in Fig. 6. The neodymium concentration in the organic phase $[\mathrm{Nd}]_{\text {org }}$ logically increases with increasing $\mathrm{Nd}(\mathrm{III})$ 35 feed concentration, up to $43 \mathrm{mmol} \cdot \mathrm{kg}^{-1}$. Thus, it can be concluded that the maximum loading of the $[\mathrm{Chol}]\left[\mathrm{Tf}_{2} \mathrm{~N}\right]$ ionic liquid with the $\mathrm{Nd}$ (III)-[Chol][hfac] complex is equal to $43 \mathrm{mmol} \cdot \mathrm{kg}^{-1}$. Beyond this point, the complex is no longer completely soluble in the organic phase and precipitates.

\section{Extraction stoichiometry}

To get a better understanding of the extraction mechanism, a slope analysis was performed. The extraction equilibrium can be described by equation (6):

$$
\mathrm{Nd}^{3+}+n \overline{\mathrm{hfac}^{-}} \rightleftarrows \overline{\mathrm{Nd}(\mathrm{hfac})_{n}^{3-n}}
$$

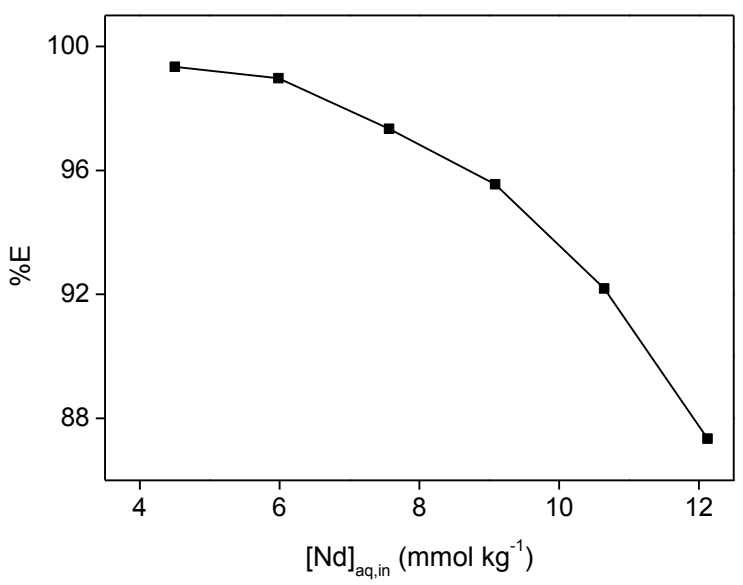

Fig. $6 \% E$ of $\mathrm{Nd}(\mathrm{III})$ with [Chol] $[\mathrm{hfac}]-[\mathrm{Chol}]\left[\mathrm{Tf}_{2} \mathrm{~N}\right]$ as a function of the initial Nd(III) concentration in the aqueous phase. $50 \mathrm{mmol} \cdot \mathrm{kg}^{-1}$ [Chol][hfac] in organic phase, $4-12 \mathrm{mmol} \cdot \mathrm{kg}^{-1} \mathrm{Nd}(\mathrm{III})$ and $0.01 \mathrm{M} \mathrm{HNO}_{3}$ in aqueous phase.

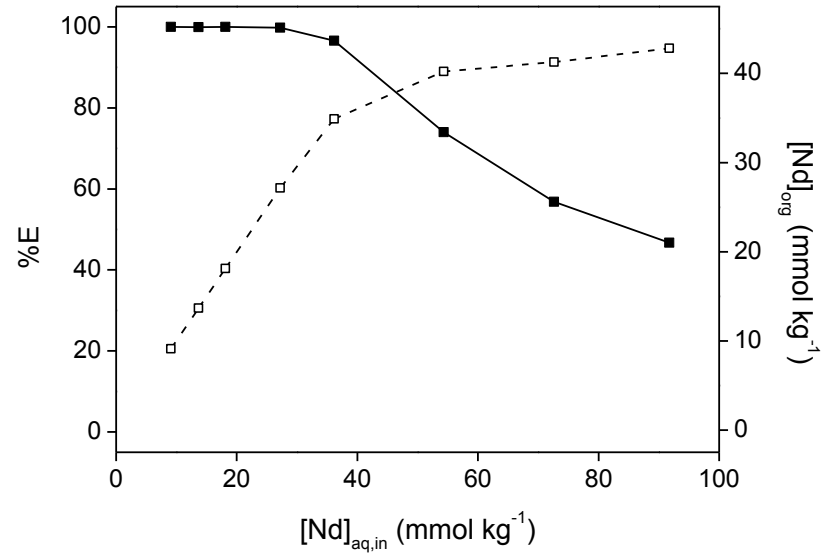

Fig. 7 Maximum loading of the organic phase: $\% E$ and $\square \mathrm{Nd}$ concentration in the organic phase after extraction with [Chol][hfac]$[\mathrm{Chol}]\left[\mathrm{Tf}_{2} \mathrm{~N}\right]$ as a function of the initial $\mathrm{Nd}(\mathrm{III})$ concentration in the aqueous phase. $144 \mathrm{mmol} \cdot \mathrm{kg}^{-1}$ [Chol][hfac] in organic phase. Equilibrium $55 \quad \mathrm{pH}$ was constant at $\mathrm{pH} 6$.

The bar indicates species in the organic phase. During the homogeneous stage of the extraction, the dissociated hexafluoroacetylacetonate anion coordinates to the $\mathrm{Nd}$ (III) ion. Upon phase separation during the settling stage, the formed ${ }_{60}$ complex diffuses to the bulk of the organic phase. The corresponding equilibrium constant $K_{e x}$ is expressed as:

$$
K_{e x}=\frac{\left[\overline{\mathrm{Nd}(\mathrm{hfac})_{n}^{3-n}}\right]}{\left[\mathrm{Nd}^{3+}\right]\left[\overline{h f a c^{-}}\right]^{n}}
$$

In this equation, the equilibrium concentration of $\mathrm{Nd}(\mathrm{hfac})_{n}^{3-n}$ is equal to the analytical concentration of neodymium in the organic ${ }_{65}$ phase $[\mathrm{Nd}]_{\text {org }}$ and $\left[\mathrm{Nd}^{3+}\right]$ is equal to the analytical concentration of neodymium in the aqueous phase, $[\mathrm{Nd}]_{a q}$. Thus, the distribution ratio $D$ can be written as:

$$
D=\frac{[\mathrm{Nd}]_{\text {org }}}{[\mathrm{Nd}]_{a q}}=\frac{\left[\overline{\mathrm{Nd}(\mathrm{hfac})_{n}^{3-n}}\right]}{\left[\mathrm{Nd}^{3+}\right]}
$$

After substitution of (8) in (7) and taking the logarithm of both 70 sides of equation (7), $\log D$ is expressed as being linearly related 


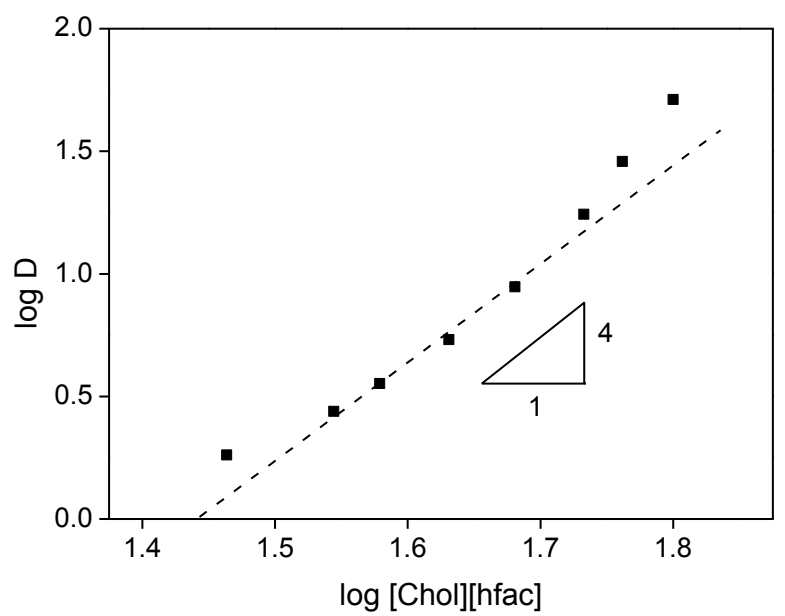

Fig. $8 \log D$ versus $\log$ [Chol][hfac] for the extraction of $\mathrm{Nd}(\mathrm{III})$ from a nitrate solution with [Chol] [hfac]-[Chol] $\left[\mathrm{Tf}_{2} \mathrm{~N}\right] .30-65 \mathrm{mmol} \cdot \mathrm{kg}^{-1}$ [Chol][hfac] in organic phase, $12 \mathrm{mmol} \cdot \mathrm{kg}^{-1} \mathrm{Nd}(\mathrm{III})$ in aqueous phase 5 initially. Equilibrium $\mathrm{pH}$ was constant at $\mathrm{pH}$ 6. Dashed line indicates a slope of 4 . The deviations at low and high extractant concentrations are discussed in the text.

to $n$ times the logarithm of [hfac ${ }^{-}$:

$$
\log D=\log K_{\text {ex }}+n \log \left[\mathrm{hfac}^{-}\right]
$$

10 The slope of a plot of $\log D$ versus $\log \left[\mathrm{hfac}^{-}\right]$is equal to $n$, which is the number of coordinated hfac ${ }^{-}$ligands per $\mathrm{Nd}(\mathrm{III})$ ion. Notice that $\left[\mathrm{hfac}^{-}\right]$is the equilibrium concentration of free hexafluoroacetylacetonate anions, which is an unknown parameter. It is approximated by the initial concentration of 15 [Chol][hfac] (in mmol $\cdot \mathrm{kg}^{-1}$ ) in the ionic liquid phase.

$\log D$ versus $\log$ [Chol][hfac] for the extraction of $\mathrm{Nd}(\mathrm{III})$ with [Chol][hfac]-[Chol] $\left[\mathrm{Tf}_{2} \mathrm{~N}\right]$ does not show a perfectly linear relation (Fig. 8). When drawing the tangent at different parts of the plot, it can be seen that the slope of the tangent varies 20 between a value of 4 at low extractant concentrations and a value larger than 4 at high extractant concentrations. The same nonlinear behavior was observed when extracting from an aqueous phase with a constant high ionic strength of $1 \mathrm{~mol} \cdot \mathrm{L}^{-1}$, by addition of $\mathrm{NaCl}$ to the aqueous phase. Thus, it can be ruled out 25 that the small deviation in slope is due to changes in the phase behavior which could influence the calculated percentage extraction. As will be described in the section 'Phase behavior' at the end this paper, it was observed that the presence of [Chol][hfac] in the ionic liquid phase had a lowering effect on the 30 cloud point. However, at an ionic strength of $1 \mathrm{~mol} \cdot \mathrm{L}^{-1}$, the mutual solubility of ionic liquid and water, and thus the mass of the phases, remains approximately constant regardless of the amount of [Chol][hfac] present. Thus, the increase in slope of the plot of $\log D$ versus $\log$ [Chol][hfac] in Fig. 8 is most likely due 35 to the approximation of [hfac $\left.{ }^{-}\right]$by the initial concentration of [Chol][hfac]. At low and intermediate extractant concentrations compared to the initial $\mathrm{Nd}(\mathrm{III})$ concentration, the equilibrium extractant concentration $\left[\mathrm{hfac}^{-}\right]$is proportional to the initial concentration of [Chol][hfac]. However, at higher concentrations 40 (excess) of extractant compared to $\mathrm{Nd}(\mathrm{III})$, this no longer holds. The initial extractant concentration of [Chol][hfac] is no longer a good approximation of the equilibrium concentration [hfac ${ }^{-}$. This explaines the increase in slope in the plot of $\log D$ versus $\log$
[Chol][hfac] with higher [Chol][hfac] concentrations. Also, at 45 very low extractant concentrations, almost no $\mathrm{Nd}$ (III) is extracted and the initial [Chol][hfac] concentration is not a good estimation of the equilibrium [hfac ${ }^{-}$] concentration.

When drawing a straight line with a slope of 4 in Fig. 8, it can be seen that this line fits well the middle part of the plot. This 50 implies that $\mathrm{Nd}(\mathrm{III})$ is extracted by [Chol][hfac] in a 1:4 stoichiometry and a tetrakis $\mathrm{Nd}(\mathrm{III})$ hexafluoroacetylacetonate complex is formed upon extraction. The formation of anionic tetrakis $\beta$-diketonate complexes is often observed for the extraction of lanthanide ions into ionic liquids. ${ }^{66}$ The availability

55 of a counter ion and the possibility for ion exchange into a second phase enable the unexpected formation of a tetrakis complex in an aqueous system. However, the slope analysis alone does provide valid proof for the extraction of a $\mathrm{Nd}(\mathrm{III})$ complex with a 1:4 stoichiometry.

\section{${ }_{60}$ Crystal structure of [Chol] $\left[\mathrm{Nd}(\mathrm{hfac})_{4}\right]$}

The assumption of the formation of a tetrakis $\mathrm{Nd}$ (III)hexafluoroacetylacetonate complex as derived above in the previous section, was confirmed with single-crystal X-ray diffraction. Upon increasing the loading of extracted $\mathrm{Nd}(\mathrm{III})$ in 65 the ionic liquid phase, crystal formation occurred during the settling (cooling) stage. Compound [Chol] $\left[\mathrm{Nd}(\mathrm{hfac})_{4}\right]$ crystallizes in the centrosymmetric space group $\mathrm{P} 2{ }_{1} / \mathrm{n}$ with one molecule in the asymmetric unit (Fig. 9). The central $\mathrm{Nd}(\mathrm{III})$ ion is coordinated by four hexafluoroacteylacetonate ligands and one 70 choline ligand to form a nine-coordinate complex with a capped square antiprism as coordination polyhedron. The choline ligand is disordered over two positions with an occupancy of 0.605(9):0.395(9). The Nd-O distances between the $\mathrm{Nd}$ and the hfac ${ }^{-}$ligands range between 2.429(4) $\AA$ and 2.489(4) $\AA$. The Nd$75 \mathrm{O}$ distances of the choline ligand are significantly larger. The distances are respectively $2.550(8) \AA$ for the first orientation and 2.618(16) $\AA$ for the second part. The second position of the choline ligand leaves room for a water solvent molecule, which interacts by hydrogen bonding with a nearby fluorine atom 80 (O52 ...F24 : 2.651(7) A, symmetry code: (i) [-X, -Y, -Z]) and the choline oxygen (O52 ... $551: 2.625(8) \AA$ ). In the crystal packing three intermolecular non classical hydrogen bonds are noticeable. Their donor acceptor distances are respectively: $\mathrm{C}(3)$....F(11) 3.352(7) $\AA, C(44) \ldots F(22) 3.075(11) \AA$ and C(44)...F(3) 3.172(9) ${ }_{85} \AA$. The crystal structure is remarkable, because it is one of the rare examples of a nine-coordinate lanthanide tetrakis $\beta$ diketonate complex. ${ }^{58}$ In general, this type of complexes has an eight-coordinate lanthanide center, with the four bidentate $\beta$ diketonate ligands saturating the first coordination sphere of the 90 lanthanide ion. ${ }^{57,67-72}$ Coordination of a water molecule to neodymium(III) tetrakis hexafluoroacetylacetonate complexes has been reported. ${ }^{73,74}$ Also in some lanthanide tetrakis 3cyanopentane-2,4-dionate complexes additional coordination of water molecules occurs to give a nine-coordinate complex. ${ }^{75}$ ${ }_{95}$ Recently, Nockemann and coworkers reported a crystal structure of a europium(III) tetrakis hexafluoroacetylacetonate complex with coordination of the oxygen atom of a imidazoliumfunctionalized diphenylphosphinoxide. ${ }^{76}$ The structure of the $[\mathrm{Chol}]\left[\mathrm{Nd}(\mathrm{hfac})_{4}\right]$ complex is somewhat similar to the latter 100 complex, since the coordinated ligand also provides the counter cation for the anionic tetrakis complex. The unusual structure of 


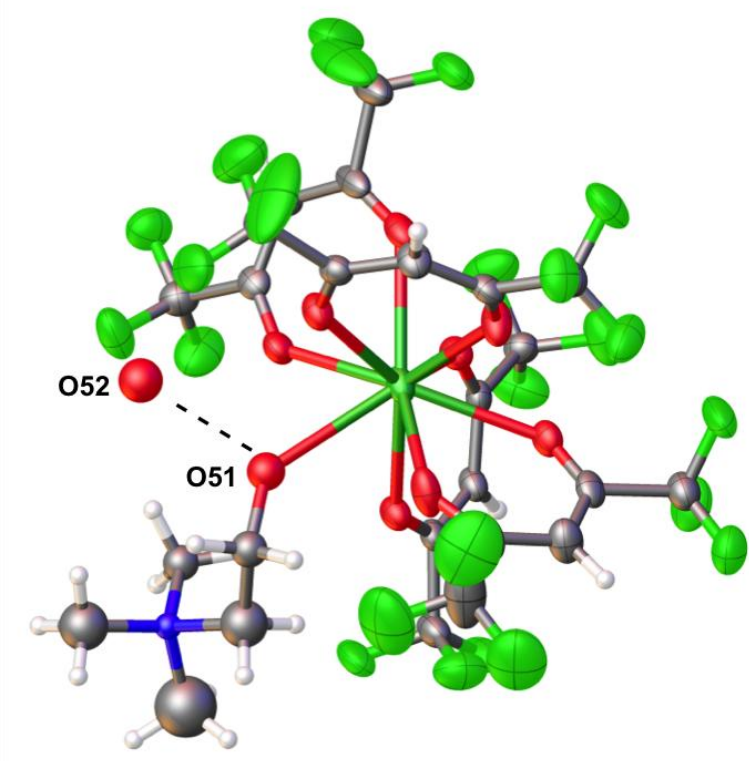

Fig. 9 Crystal structure of [Chol] $\left[\mathrm{Nd}(\mathrm{hfac})_{4}\right]$. Only one part of the choline ligand orientation is shown.

[Chol][ $\left.\mathrm{Nd}(\mathrm{hfac})_{4}\right]$ is most likely due to a combination of different 5 factors: the increased Lewis acidity of the neodymium(III) ion due to the fluorinated ligands, sterically little demanding $\beta$ diketonate ligands and a small cation with a Lewis basic group (the choline cation with its primary alcohol function).

\section{Ion exchange}

10 To preserve electrical neutrality upon extraction of the tetrakis $\mathrm{Nd}(\mathrm{III})$ complex, ion exchange has to occur between the organic and the aqueous phase. Per extracted Nd(III) ion, one of the four dissociated $\mathrm{Chol}^{+}$cations neutralizes the extracted $[\mathrm{Chol}]\left[\mathrm{Nd}(\mathrm{hfac})_{4}\right]$ complex. The other three $\mathrm{Chol}^{+}$cations either 15 stay in the organic phase or diffuse to the aqueous phase. When the $\mathrm{Chol}^{+}$cations are staying in the organic phase, nitrate ions should be co-extracted to neutralize the three $\mathrm{Chol}^{+}$cations. To determine which hypothesis is valid, extraction was carried out from a bromide solution. As described in the beginning of the ${ }_{20}$ paper, it was seen that the type of neodymium salt, being nitrate or chloride, did not influence the extraction performance. Since measurement of nitrate or chloride content by TXRF is difficult, extraction was performed from a bromide solution. TXRF is a suitable technique to measure bromide content in ionic liquids. ${ }^{77}$

${ }_{25}$ It was observed that no bromide was co-extracted with the metal ions, which implies that the three $\mathrm{Chol}^{+}$cations diffuse to the aqueous phase. So, in exchange for one extracted $\mathrm{Nd}(\mathrm{III})$ ion, three $\mathrm{Chol}^{+}$are transferred to the aqueous phase. To confirm the ion-exchange mechanism, the influence of the addition of choline 30 chloride to the aqueous phase was examined. It was observed that the $\% E$ decreased significantly with increasing choline chloride content (Fig. 10). Thus, addition of choline chloride to the aqueous phase pushes back the extraction equilibrium, which confirms that $\mathrm{Chol}^{+}$cations migrate to the aqueous phase upon ${ }_{35} \mathrm{Nd}(\mathrm{III})$ extraction.

Ion exchange is a typical mechanism for extraction of metal ions into ionic liquids..$^{59,78,79}$ Depending on the type of extracted

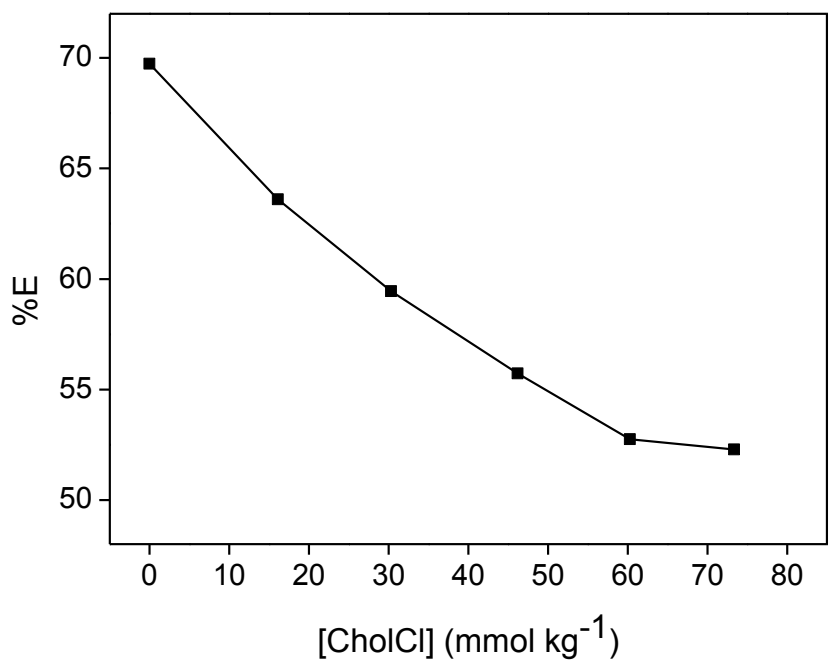

Fig. 10 Influence of the addition of choline chloride to the aqueous phase on the $\% E$ of $\mathrm{Nd}(\mathrm{III})$ from a nitrate solution with [Chol][hfac]-

[Chol][Tf $\left.{ }_{2} \mathrm{~N}\right] .50 \mathrm{mmol} \cdot \mathrm{kg}^{-1}$ [Chol][hfac] in organic phase, $12 \mathrm{mmol} \cdot \mathrm{kg}^{-1}$ $\mathrm{Nd}(\mathrm{III})$ in aqueous phase. Equilibrium $\mathrm{pH}$ was constant.

complex, being anionic or cationic, anions or cations of the ionic liquid diffuse to the aqueous phase in exchange for the extracted 45 metal complex. In some extraction systems with ionic liquids, the occurrence of ion exchange enhances metal extraction to the ionic liquid phase compared to extraction to the organic phase with traditional molecular diluents and could be considered an advantage. ${ }^{59}$ Still, loss of ions of the ionic liquid to the aqueous 50 phase by the ion exchange mechanism is a major limitation for the practical application of ionic liquid solvent extraction systems. Part of the ionic liquid is lost and the aqueous phase is contaminated. Therefore, ion exchange should be avoided if possible. ${ }^{80}$ A possibility to prevent the loss of $\mathrm{Chol}^{+}$to the 55 aqueous phase when extracting $\mathrm{Nd}(\mathrm{III})$ with [Chol][hfac] is the replacement of three of the [Chol][hfac] ionic liquid molecules by the molecular acidic form of the extractant, namely hexafluoroacetylacetone (Hhfac). Upon extraction of one $\mathrm{Nd}$ (III) ion, Hhfac exchanges its protons to coordinate to the $\mathrm{Nd}(\mathrm{III})$ ${ }_{60}$ center. The fourth $\mathrm{hfac}^{-}$ligand, is provided together with the counter ion by the [Chol][hfac] ionic liquid moiety. However, it was observed that about $50 \%$ less $\mathrm{Nd}(\mathrm{III})$ was extracted compared to extraction by [Chol][hfac] only. In order to compare the obtained results with the results of extraction with only ${ }_{65}$ [Chol][hfac], a small amount of $\mathrm{NaOH}(35 \mu \mathrm{L}, 1 \mathrm{M})$ was added to the extraction mixture to obtain the same equilibrium $\mathrm{pH}$ as in previous experiments. The same amount of hfac ${ }^{-}$was used (50 $\mathrm{mmol} \cdot \mathrm{kg}^{-1}$ ), but $75 \mathrm{~mol} \%$ was added as Hhfac and $25 \mathrm{~mol} \%$ as [Chol][hfac], instead of $100 \mathrm{~mol} \%$ as [Chol][hfac]. This indicates 70 that the diffusion of $\mathrm{Chol}^{+}$ions to the aqueous phase significantly enhances extraction, which is in line with observations described in the literature. ${ }^{78}$

\section{Stripping studies}

The extracted $\mathrm{Nd}$ (III) ions were again stripped from the loaded $75[\mathrm{Chol}]\left[\mathrm{Tf}_{2} \mathrm{~N}\right]$ phase by mixing with a diluted $\mathrm{HNO}_{3}$ solution. When acid was added to the loaded $[\mathrm{Chol}]\left[\mathrm{Tf}_{2} \mathrm{~N}\right]$, the neodymium complex dissociated into free metal ion and protonated ligands: 


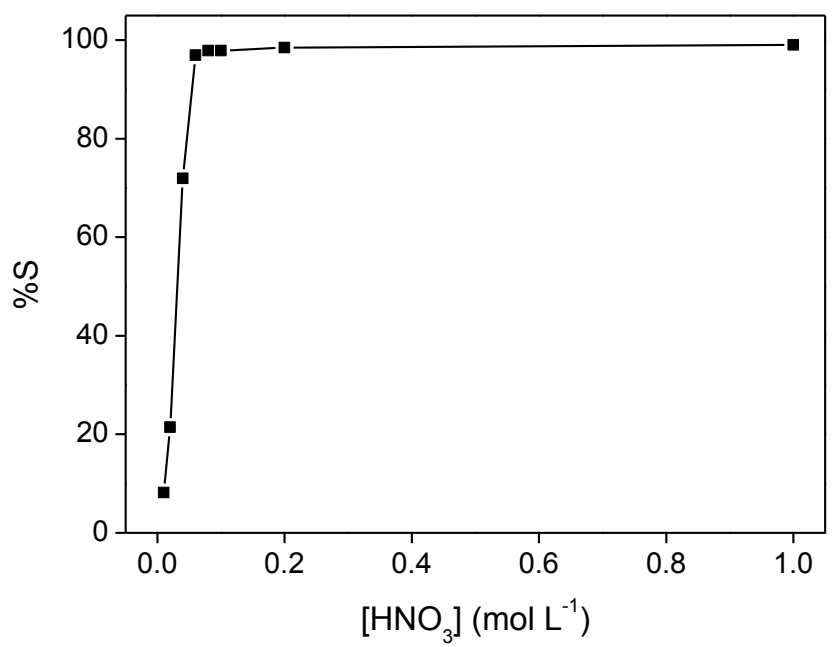

Fig. 11 Stripping of a $[\mathrm{Chol}]\left[\mathrm{Tf}_{2} \mathrm{~N}\right]$ phase, loaded with $\mathrm{Nd}(\mathrm{III})$ (12 $\mathrm{mmol} \cdot \mathrm{kg}^{-1}$ ) after extraction with [Chol][hfac], with varying $\mathrm{HNO}_{3}$ concentration.

$$
\begin{gathered}
\overline{[\text { Chol }]\left[\mathrm{Nd}(\mathrm{hfac})_{4}\right]}+3 \mathrm{H}^{+} \\
\rightleftarrows \mathrm{Nd}^{3+}+3 \overline{\mathrm{Hhfac}}+\overline{[\mathrm{Chol}][\mathrm{hfac}]}
\end{gathered}
$$

Mixing of the loaded [Chol] $\left[\mathrm{Tf}_{2} \mathrm{~N}\right]$ with a diluted $\mathrm{HNO}_{3}$ solution with a concentration of $0.1 \mathrm{M}$ resulted in $98 \%$ stripping efficiency of $\mathrm{Nd}(\mathrm{III})$ from the ionic liquid phase. All metal ions 10 were removed by stripping with a $1 \mathrm{M} \mathrm{HNO}_{3}$ solution (Fig. 11). It is preferable to perform stripping in one step. Each time the ionic liquid phase is brought in contact with an aqueous solution, part of the $[\mathrm{Chol}]\left[\mathrm{Tf}_{2} \mathrm{~N}\right]$ diluent dissolves in the aqueous phase, which leads to significant losses of valuable ionic liquid. Determination 15 of the loss of [Chol] $\left[\mathrm{Tf}_{2} \mathrm{~N}\right]$ is not straightforward, since these losses depend on the composition of the extraction mixture (acid concentration, metal concentration, extractant concentration). After stripping, the ionic liquid phase was available for a new extraction step. Some $\mathrm{HNO}_{3}$ was dissolved in the ionic liquid ${ }_{20}$ phase, but this was easily neutralized with a base, such as $\mathrm{NaOH}$.

\section{Decomposition of [Chol][hfac]}

The extraction efficiency of the [Chol][hfac] extractant decreased when heated for a longer time at elevated temperature. Moreover, the extraction performance of the ionic liquid phase also 25 decreased significantly with increasing storage time (Fig. 12). After 14 days of storage at room temperature $\left(20^{\circ} \mathrm{C}\right), \% E$ for the extraction of $\mathrm{Nd}(\mathrm{III})$ was reduced to less than $50 \%$ of the percentage extraction at day 1 . The degradation of the $[\mathrm{Chol}][\mathrm{hfac}]-[\mathrm{Chol}]\left[\mathrm{Tf}_{2} \mathrm{~N}\right]$ mixture is slowed down by storing the ${ }_{30}$ mixture at lower temperatures (for instance in a refrigerator at 6 ${ }^{\circ} \mathrm{C}$ ), but still $\% E$ decreased with more than $10 \%$ after 14 days of storage at $6{ }^{\circ} \mathrm{C}$. The decrease in extraction performance was due to reactions between hexafluoroacetylacetone and water, forming

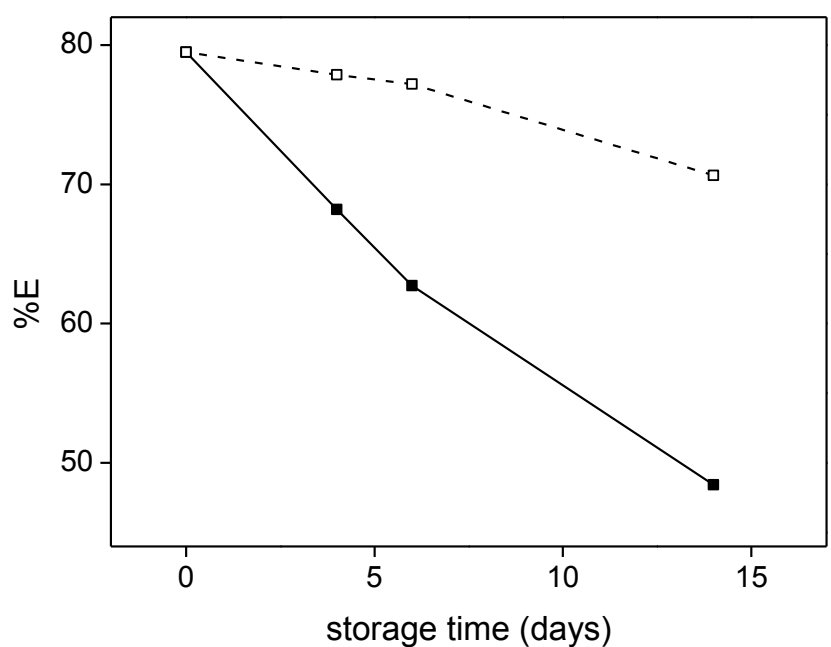

35 Fig. 12 Decrease in extraction performance of a [Chol][hfac][Chol][Tf2N] mixture containing $8 \mathrm{wt} \%$ water, as a function of storage time and storage temperature: $20^{\circ} \mathrm{C}$ (solid line) and $6{ }^{\circ} \mathrm{C}$ (dashed line). Initial amount of $\mathrm{HNO} 3$ in the aqueous phase is $0.01 \mathrm{mmol}$.

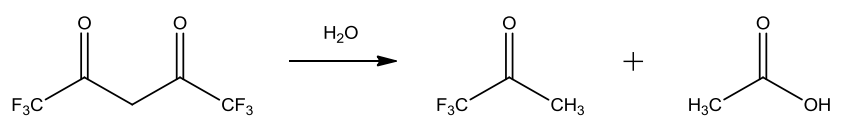

40 Fig. 13 Decomposition reaction of hexafluoroacetylacetone with water to trifluoroacetone and trifluoroacetic acid.

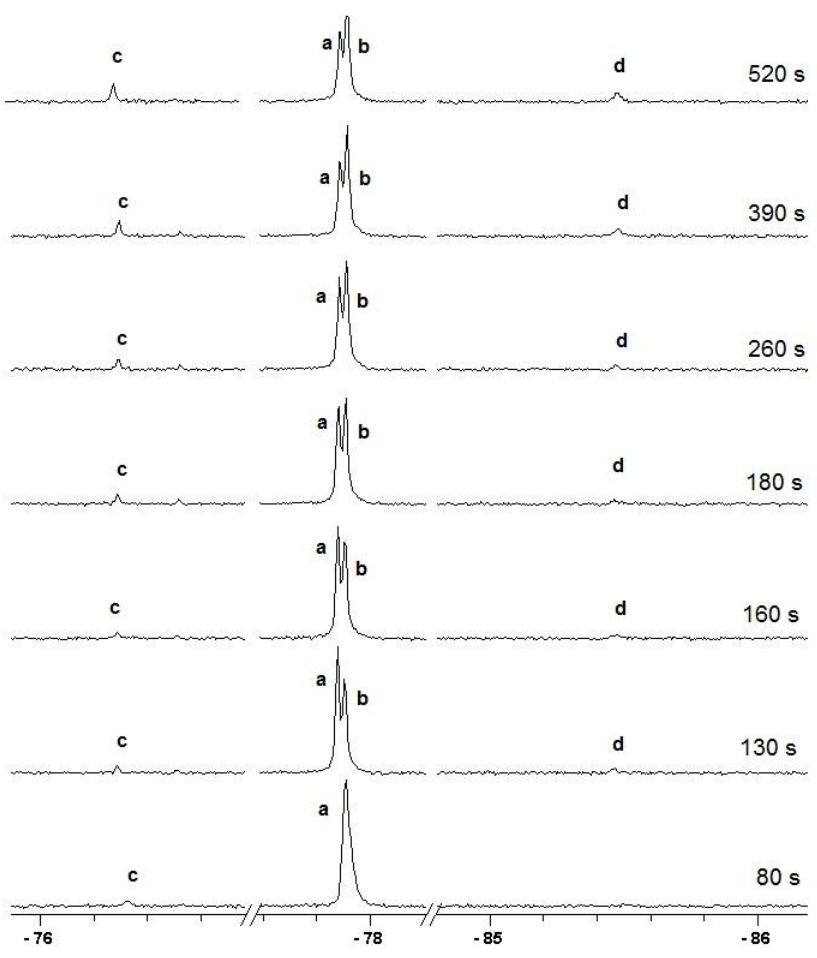

Fig. 14 Decomposition reaction of [Chol] [hfac] with water at $80{ }^{\circ} \mathrm{C}$ 45 monitored by ${ }^{19} \mathrm{~F}$ NMR spectroscopy.

decomposition products such as trifluoroacetic acid and trifluoroacetone (Fig. 13) or Hhfac-water adducts, such as the gem-diol product. ${ }^{81,82}$

It has also been described in the literature that dry [Chol][hfac] 50 has a low thermal stability. ${ }^{56}$ The decomposition temperature 


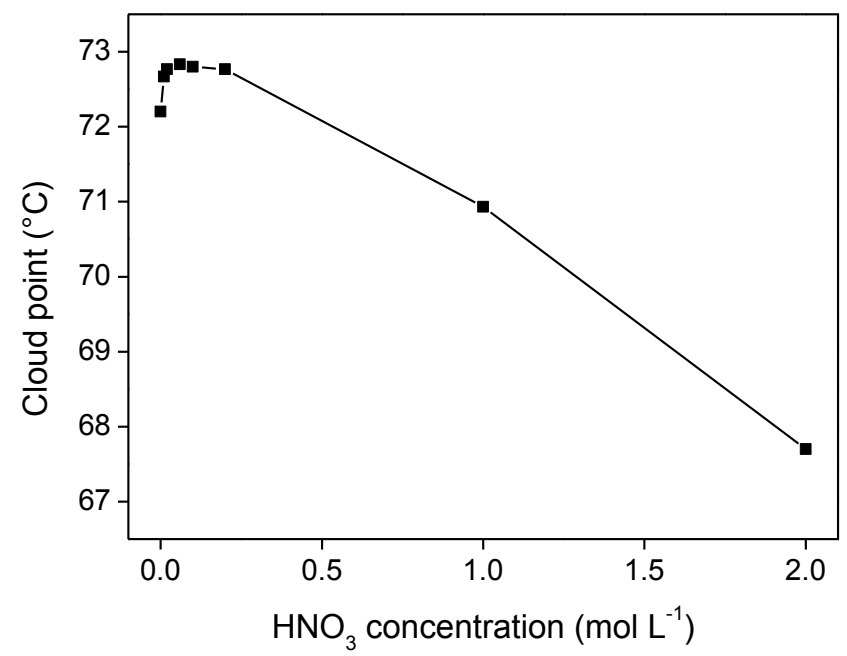

Fig. 15 Influence of the concentration of $\mathrm{HNO}_{3}$ in the aqueous feed on the cloud point of a [Chol] $\left[\mathrm{Tf}_{2} \mathrm{~N}\right]-\mathrm{H}_{2} \mathrm{O}$ mixture. Standard deviation on cloud point is $0.2^{\circ} \mathrm{C}$.

5 determined with TGA is stated to be equal to $83 \pm 3{ }^{\circ} \mathrm{C}$, but it can be seen from the reported thermogram that a mass loss already occurs at temperatures below $80{ }^{\circ} \mathrm{C}$.

Decomposition of [Chol][hfac] was monitored by ${ }^{19} \mathrm{~F}$ NMR measurements. A mixture of [Chol][hfac] and water was kept at $1080{ }^{\circ} \mathrm{C}$ and a ${ }^{19} \mathrm{~F}$ NMR spectrum was recorded every $26 \mathrm{~s}$. At the start of the experiment, only one peak (a, at $-77.89 \mathrm{ppm})$ was visible in the ${ }^{19} \mathrm{~F}$ NMR spectrum, which was contributed to the $\mathrm{CF}_{3}$ groups of hfac'. Nearly immediately after the start of the experiment, it was seen that this peak slowly diminished. At the 15 same time, a second peak appeared near the peak of $\mathrm{hfac}^{-}(\mathbf{b}$, at $77.91 \mathrm{ppm}$ ) (Fig. 14), which is most likely caused by the formation of trifluoroacetic acid. Moreover, a third peak, most likely assigned to trifluoroacetone, and a fourth peak appeared at $-85.48 \mathrm{ppm}$ (d) and $-76.29 \mathrm{ppm}$ (c), respectively. These 20 observations showed that decomposition is fast at $80{ }^{\circ} \mathrm{C}$. Thus, it is preferable to perform extractions on a short time scale and to avoid long mixing times at elevated temperatures. This conclusion confirms that it is preferable to use HLLE, since it can be executed on a very short time scale. In this way, the extraction 25 process is fast and decomposition is avoided as much as possible.

\section{Phase behavior}

The addition of extractants and the presence of acids and ions in the aqueous phase have an influence on the phase behavior and the mutual solubility of the ionic liquid and water. ${ }^{83-85}$ To 30 examine the effect of the addition of [Chol] [hfac] and $\mathrm{HNO}_{3}$ to the extraction mixture, the cloud point of $[\mathrm{Chol}]\left[\mathrm{Tf}_{2} \mathrm{~N}\right]-\mathrm{H}_{2} \mathrm{O}$ mixtures containing varying amounts of $\mathrm{HNO}_{3}$ and [Chol][hfac] was determined. The cloud point is the temperature at which the mixture becomes cloudy upon cooling. At this point, water and 35 the ionic liquid are no longer completely miscible and they will phase separate. An ionic liquid rich organic phase is formed, together with an ionic liquid lean aqueous phase. The presence of $\mathrm{HNO}_{3}$ at low concentrations $(<0.5 \mathrm{M})$ in the $\mathrm{IL}-\mathrm{H}_{2} \mathrm{O}$ mixture increased the cloud point with approximately $1{ }^{\circ} \mathrm{C}$. At higher $40 \mathrm{HNO}_{3}$ concentrations (> $1 \mathrm{M}$ ) however, the cloud point decreased several degrees Celsius (Fig. 15). These observations are similar as the phase behavior of imidazolium ionic liquids described in

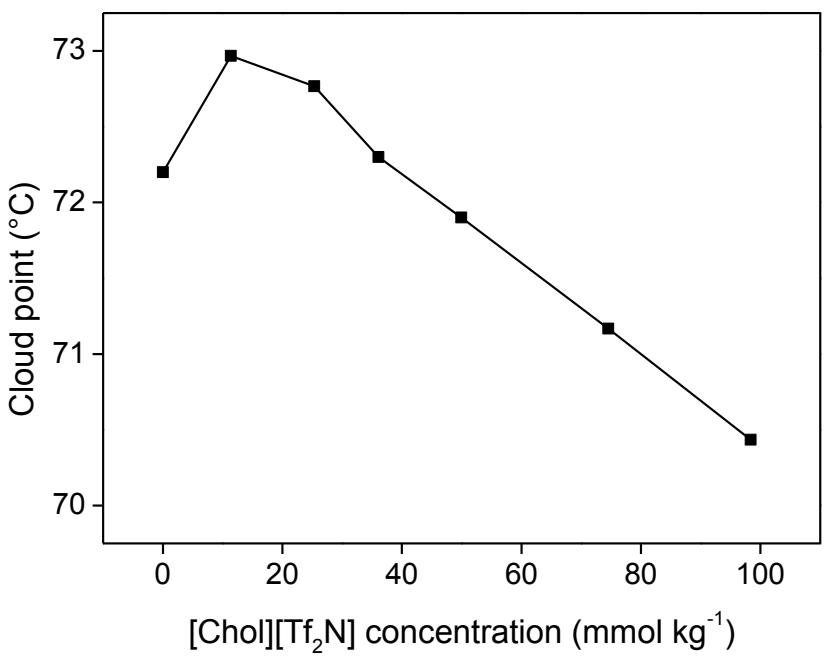

Fig. 16 Influence of the concentration of [Chol][hfac] in the organic phase 45 on the cloud point of a $[\mathrm{Chol}]\left[\mathrm{Tf}_{2} \mathrm{~N}\right]-\mathrm{H}_{2} \mathrm{O}$ mixture. Standard deviation on cloud point is $0.2{ }^{\circ} \mathrm{C}$.

the literature. ${ }^{83,85}$ The change in water solubility of a solute upon addition of certain ions is related to salting-in/salting-out effects. A decrease in water solubility is known as salting-out, an increase 50 in solubility is known as salting-in. The properties of different ions with respect to the salting of ionic liquids follow the Hofmeister series. $^{85}$ It must be noted that these salting phenomena are complex and depend both on the type of solute and concentration of the salting ion. The nitrate ion is located at 55 the end of the Hofmeister series, i.e. it generally has a weak salting-out or even a salting-in effect on the solubility of organic compounds in water. Thus, the slight increase in cloud point at low $\mathrm{HNO}_{3}$ concentrations, corresponding to a slight decrease in water solubility of the ionic liquid and thus a small salting-out ${ }_{60}$ effect is also in line with observations described in the literature, where it was stated that the salting effect (in or out) of a certain ion depends on the concentration of the corresponding salt. ${ }^{83}$ The addition of the extractant [Chol] [hfac] to the [Chol] $\left[\mathrm{Tf}_{2} \mathrm{~N}\right]-\mathrm{H}_{2} \mathrm{O}$ mixture had a similar effect on the cloud point. At low 65 [Chol] [hfac] concentrations, the cloud point increased $1{ }^{\circ} \mathrm{C}$ (Fig. 16). At higher concentrations ( $>50 \mathrm{mmol} \cdot \mathrm{kg}^{-1}$ ), the cloud point decreased again below $72.2{ }^{\circ} \mathrm{C}$, which is the cloud point of a mixture without the presence of any additives.

\section{Comparison with the $[\mathrm{Hbet}]\left[\mathrm{Tf}_{2} \mathrm{~N}\right]$ system}

70 In previous work, the protic ionic liquid $[\mathrm{Hbet}]\left[\mathrm{Tf}_{2} \mathrm{~N}\right]$ was presented for HLLE of rare-earth ions. ${ }^{19,20}$ Because pure [Hbet] $\left[\mathrm{Tf}_{2} \mathrm{~N}\right]$ only poorly extracts rare-earth ions, an extractant was added. [Hbet] $\left[\mathrm{Tf}_{2} \mathrm{~N}\right]$ has a high acidity due to the presence of the carboxyl function on the cation and typical acidic extractants 75 could not be used and zwitterionic betaine was added as an extractant. However, relatively high amounts of betaine (200 $\mathrm{g} \cdot \mathrm{kg}^{-1}$ ) were required to obtain good extraction efficiencies. The $[\mathrm{Chol}]\left[\mathrm{Tf}_{2} \mathrm{~N}\right]$ ionic liquid described in this paper is similar to [Hbet] $\left[\mathrm{Tf}_{2} \mathrm{~N}\right]$. It has a similar chemical structure as [Hbet] $\left[\mathrm{Tf}_{2} \mathrm{~N}\right]$, 80 but with a hydroxyl function on the cation instead of a carboxyl function, making it less acidic. They both show a UCST-type of phase behavior with water. The critical temperature of $[\mathrm{Chol}]\left[\mathrm{Tf}_{2} \mathrm{~N}\right]\left(72{ }^{\circ} \mathrm{C}\right)$ is higher than $[\mathrm{Hbet}]\left[\mathrm{Tf}_{2} \mathrm{~N}\right]\left(55^{\circ} \mathrm{C}\right)$, so higher temperatures are required during HLLE to reach the 
homogeneous stage. Because of the lower acidity of [Chol] $\left[\mathrm{Tf}_{2} \mathrm{~N}\right]$ in water, it is possible to use this ionic liquid as a diluent in combination with (polar) acidic extractants, such as $\beta$-diketones. In the extraction system described in this paper, the [Chol][hfac] 5 extractant is added to the organic phase in stoichiometric amounts to obtain almost full extraction of $\mathrm{Nd}(\mathrm{III})$, whereas an excess of zwitterionic betaine was required to obtain high extraction efficiencies of $\mathrm{Nd}(\mathrm{III})$ in $[\mathrm{Hbet}]\left[\mathrm{Tf}_{2} \mathrm{~N}\right]$.

\section{Conclusions}

10 It was shown that the ionic liquid $[\mathrm{Chol}]\left[\mathrm{Tf}_{2} \mathrm{~N}\right]$ is a suitable diluent for the homogeneous liquid-liquid extraction of $\mathrm{Nd}(\mathrm{III})$ from aqueous solution with [Chol][hfac] as extractant. Homogeneous liquid-liquid extraction is a novel energy-efficient technique to perform ionic liquid solvent extraction, which is 15 based on the formation of a homogeneous phase during mixing. $[\mathrm{Chol}]\left[\mathrm{Tf}_{2} \mathrm{~N}\right]$ shows thermomorphic behavior in water, with an UCST of $72{ }^{\circ} \mathrm{C}$. The influence of several extraction parameters was studied, including extractant concentration, $\mathrm{pH}$ and $\mathrm{Nd}$ (III) feed concentration. At stoichiometric ratios of $\mathrm{Nd}(\mathrm{III})$ and 20 [Chol][hfac], nearly all metal ions were extracted and loadings in the ionic liquid phase up to $40 \mathrm{mmol} \cdot \mathrm{kg}^{-1}$ were achieved. A speciation study was performed to determine the extraction mechanism. Via slope analysis and crystal structure determination, it was shown that $\mathrm{Nd}$ (III) was extracted via an 25 anionic tetrakis(hexafluoroacetylacetonato)neodymate(III) complex, with a choline cation as counter ion. Upon extraction, ion exchange occurred and three $\mathrm{Chol}^{+}$ions were transferred to the aqueous phase. The crystal structure determination of the extracted [Chol] $\left[\mathrm{Nd}(\mathrm{hfac})_{4}\right]$ complex showed that the $\mathrm{Chol}^{+}$ 30 counter ion was coordinated to the $\mathrm{Nd}(\mathrm{III})$ center, forming a ninecoordinate complex. This is one of the rare examples of coordination of the counter ion in tetrakis lanthanide $\beta$-diketonate complexes to the lanthanide(III) ion. Finally, $\mathrm{Nd}(\mathrm{III})$ was successfully stripped from the loaded ionic liquid phase with a 1 ${ }_{35} \mathrm{M} \mathrm{HNO}_{3}$ solution.

\section{Acknowledgments}

This research was financially supported by the FWO-Flanders (research project G.0900.13), and KU Leuven (projects GOA/13/008 and IOF-KP RARE ${ }^{3}$ ). The authors thank the 40 Hercules Foundation for supporting the purchase of equipment through the project AKUL/09/0035, Molybdenum high-energy $\mathrm{X}$-ray source for in-situ diffraction studies of advanced materials and single crystals. B.O. thanks Karel Duerinckx for assistance to the ${ }^{19} \mathrm{~F}$ NMR measurements and Tom Vander Hoogerstraete for

45 useful scientific discussions. Support by IoLiTec (Heilbronn, Germany) is also gratefully acknowledged.

\section{Notes and references}

${ }^{a}$ KU Leuven, Department of Chemistry, Celestijnenlaan 200F, P;O. Box 2404, 3001 Leuven, Belgium Fax: +32 1632 7446; E-mail:

50 Koen.Binnemans@chem.kuleuven.be

$\dagger$ Electronic Supplementary Information (ESI) available: Crystallographic CIF file. See DOI: 10.1039/b000000x/
1 J. Rydberg, M. Cox, C. Musikas and G. R. Choppin, Solvent

55 Extraction: Principles and Practice, Marcel Dekker, Inc., New York, 2004, edn. 2.

2 C. K. Gupta and N. Krishnamurthy, Int. Mat. Rev., 1992, 37, 197248.

3 C. K. Gupta, N. Krishnamurthy, Extractive Metallurgy of Rare

60 Earths, CRC Press, Boca Raton, 2005.

4 M. L. Dietz, Sep. Sci. Technol., 2006, 41, 2047-2063.

5 Y. Liu, J. Chen and D. Li, Sep. Sci. Technol., 2012, 47, 223-232.

6 H. Zhao, S. Xia and P. Ma, J. Chem. Technol. Biot., 2005, 80, 10891096.

657 T. Welton, Chem. Rev., 1999, 99, 2071-2083.

8 K. R. Seddon, J. Chem. Technol. Biot., 1997, 68, 351-356.

9 P. Wasserscheid and T. Welton, in Ionic Liquids in Synthesis, ed. P. Wasserscheid, T. Welton, Wiley-VCH, Weinheim, edn. 2, 2007, ch. 3, pp. 41-118.

7010 P. Wasserscheid, T. Welton, Ionic Liquids in Synthesis, ed. P. Wasserscheid and T. Welton, Wiley-VCH, Weinheim, 2002.

11 R. D. Rogers and K. R. Seddon, Science, 2003, 302, 792-793.

12 N. V. Plechkova and K. R. Seddon, Chem. Soc. Rev., 2008, 37, 123150.

7513 M. Freemantle, An Introduction to Ionic Liquids, RSC Publishing, Cambridge, 2009.

14 G. Huddleston and D. Rogers, Chem. Commun., 1998, 1765-1766.

15 J. McFarlane, W. B. Ridenour, H. Luo, R. D. Hunt, D. W. DePaoli and R. X. Ren, Sep. Sci. Technol., 2005, 40, 1245-1265.

8016 C. F. Poole and S. K. Poole, J. Chromatogr. A, 2010, 1217, 22682286.

17 G. Yu, D. Zhao, L. Wen, S. Yang and X. Chen, AIChE J., 2012, 58, 2885-2899.

18 S. Wellens, R. Goovaerts, C. Moller, J. Luyten, B. Thijs and K.

85 Binnemans, Green Chem., 2013, 15, 3160-3164.

19 T. Vander Hoogerstraete, B. Onghena and K. Binnemans, J. Phys. Chem. Lett., 2013, 4, 1659-1663.

20 T. Vander Hoogerstraete, B. Onghena and K. Binnemans, Int. J. Mol. Sc., 2013, 14.

9021 Y. Fukaya, K. Sekikawa, K. Murata, N. Nakamura and H. Ohno, Chem. Commun., 2007, 3089-3091.

22 Y. Fukaya and H. Ohno, Phys. Chem. Chem. Phys., 2013, 15, 40664072.

23 K. Fukumoto and H. Ohno, Angew. Chem. Int. Ed, 2007, 46, $1852-$

$95 \quad 1855$.

24 Y. Kohno and H. Ohno, Phys. Chem. Chem. Phys., 2012, 14, 50635070.

25 P. Nockemann, B. Thijs, S. Pittois, J. Thoen, C. Glorieux, K. Van Hecke, L. Van Meervelt, B. Kirchner and K. Binnemans, J. Phys. Chem. B, 2006, 110, 20978-20992.

26 P. Nockemann, K. Binnemans, B. Thijs, T. N. Parac-Vogt, K. Merz, A. V. Mudring, P. C. Menon, R. N. Rajesh, G. Cordoyiannis, J. Thoen, J. Leys and C. Glorieux, J. Phys. Chem. B, 2009, 113, 1429-1437.

10527 K. Murata, S. Ikeda and Y. Yokoyama, Anal. Chem., 1972, 44, 805810.

28 H. Ebrahimzadeh, Y. Yamini, F. Kamarei and S. Shariati, Anal. Chim. Acta, 2007, 594, 93-100.

29 A. Schaadt and H. J. Bart, Chem. Eng. Technol., 2003, 26, 469-472.

11030 J. D. Lamb and R. T. Peterson, Sep. Sci. Technol., 1995, 30, 32373244.

31 A. R. Ghiasvand, S. Shadabi, E. Mohagheghzadeh and P. Hashemi, Talanta, 2005, 66, 912-916.

32 A. R. Ghiasvand and E. Mohagheghzadeh, Anal. Sci., 2004, 20, $917-$ 115919.

33 S. Gao, H. Jin, J. You, Y. Ding, N. Zhang, Y. Wang, R. Ren, R. Zhang and H. Zhang, J. Chromatogr. A, 2011, 1218, 7254-7263. 
34 M. A. Farajzadeh, M. Bahram, S. Zorita and B. G. Mehr, J. Hazard. Mater., 2009, 161, 1535-1543.

35 A. N. Anthemidis and K. I. Ioannou, Talanta, 2009, 80, 413-421.

36 T. Golan, G. Dahan, Z. Ludmer, N. Brauner and A. Ullmann, Chem. Eng. J, 2014, 236, 47-58.

37 N. Alizadeh and K. Ashtari, Sep. Purif. Technol., 2005, 44, 79-84.

38 M. H. Hosseini and N. Alizadeh, Ind. Eng. Chem. Res., 2010, 49, 7068-7073.

39 Y. Elistratova, A. R. Mustafina, D. A. Tatarinov, V. F. Mironov, V.

10 A. Burilov, I. G. Tananaev and A. I. Konovalov, Russ. Chem. Bull., 2011, 60, 790-796.

40 J. Z. Xu, N. Rajapakse and H. L. Finston, Radiochim. Acta, 1990, 49, 135-140.

41 A. Takahashi, Y. Ueki and S. Igarashi, Anal. Chim. Acta, 1999, 387, $15 \quad 71-75$.

42 K. Sasaki, K. Takao, T. Suzuki, T. Mori, T. Arai and Y. Ikeda, Dalton Trans., 2014, 43, 5648-5651.

43 I. A. Shkrob, T. W. Marin and M. P. Jensen, Ind. Eng. Chem. Res., 2014, 53, 3641-3653.

2044 K. Binnemans, P. T. Jones, B. Blanpain, T. Van Gerven, Y. Yang, A. Walton and M. Buchert, J. Clean. Prod., 2013, 51, 1-22.

45 T. Vander Hoogerstraete, S. Wellens, K. Verachtert and K. Binnemans, Green Chem., 2013, 15, 919-927.

46 T. Itakura, R. Sasai and H. Itoh, J. Alloys Compd., 2006, 408-412,

25 1382-1385.

47 M. Itoh, K. Miura and K. i. Machida, J. Alloys Compd., 2009, 477, 484-487.

48 O. Takeda, K. Nakano and Y. Sato, Mater. Trans., 2014, 55, 334341.

3049 H. Na, Y. Kim, H. Son, I. Jung and H. Choi, Curr. Nanosc., 2014, 10, 128-130.

50 H. S. Yoon, C. J. Kim, K. Chung, S. J. Lee, A. R. Joe, Y. H. Shin, S. I. Lee, S. J. Yoo and J. G. Kim, Korean J. Chem. Eng., 2014, 31, 706-711.

3551 C. H. Lee, Y. J. Chen, C. H. Liao, S. Popuri, S. L. Tsai and C. E. Hung, Metall. Mat. Trans. A, 2013, 44, 5825-5833.

52 J. P. Rabatho, W. Tongamp, Y. Takasaki, K. Haga and A. Shibayama, J. Mater. Cycles. Waste Manag., 2013, 15, 171-178.

53 M. Nakamoto, K. Kubo, Y. Katayama, T. Tanaka and T. Yamamoto,

$40 \quad$ Metall. Mater. Trans. B, 2012, 43, 468-476.

54 Y. Baba, F. Kubota, N. Kamiya and M. Goto, Solv. Extr. Res. Develop. Jpn., 2014, 15, 193-198.

55 Y. Kikuchi, M. Matsumiya and S. Kawakami, Solv. Extr. Res. Develop. Jpn., 2014, 21, 137-145.

4556 S. Pandey, G. A. Baker, L. Sze, S. Pandey, G. Kamath, H. Zhao and S. N. Baker, New J. Chem., 2013, 37, 909-919.

57 H. Mehdi, K. Binnemans, K. Van Hecke, L. Van Meervelt and P. Nockemann, Chem. Commun., 2010, 46, 234-236.

58 K. Binnemans, in Handbook on the Physics and Chemistry of Rare

50 Earths, ed. K. A. Gschneidner Jr., J. C. G. Bünzli, V. K. Pecharsky, Elsevier, Amsterdam, edn. 35, 2005, ch. 225, pp. $107-$ 272.

59 I. Billard, A. Ouadi and C. Gaillard, Anal. Bioanal. Chem., 2011, 400, 1555-1566.
5560 N. Hirayama, Solv. Extr. Res. Develop. Jpn., 2011, 18, 1-14.

61 M. P. Jensen, M. Borkowski, I. Laszak, J. V. Beitz, P. G. Rickert and M. L. Dietz, Sep. Sci. Technol., 2012, 47, 233-243.

62 K. Binnemans, Chem. Rev., 2007, 107, 2592-2614.

63 G. Sheldrick, Acta Cryst., 2008, A64, 112-122.

6064 O. V. Dolomanov, L. J. Bourhis, R. J. Gildea, J. A. K. Howard and H. Puschmann, J. Appl. Cryst., 2009, 42, 339-341.

65 CrysAlis PRO, Agilent Technologies UK Ltd, Yarnton, Oxfordshire, England, 2012.

66 M. P. Jensen, J. A. Neuefeind, J. V. Beitz, S. Skanthakumar and L.

65 Soderholm, J. Am. Chem. Soc., 2003, 125, 15466-15473.

67 R. Van Deun, P. Van Der Voort, I. Van Driessche and K. Van Hecke, Acta Cryst., 2012, E68, m111-m112.

68 P. Nockemann, E. Beurer, K. Driesen, R. Van Deun, K. Van Hecke, L. Van Meervelt and K. Binnemans, Chem. Commun., 2005, 4354-4356.

69 S. F. Tang and A. V. Mudring, Eur. J. Inorg. Chem., 2009, 2009, 2769-2775

70 K. Lunstroot, K. Driesen, P. Nockemann, K. Van Hecke, L. Van Meervelt, C. Gorller-Walrand, K. Binnemans, S. Bellayer, L.

75 Viau, J. Le Bideau and A. Vioux, Dalton Trans., 2009, 298-306.

71 K. Lunstroot, P. Nockemann, K. Van Hecke, L. Van Meervelt, C. Görller-Walrand, K. Binnemans and K. Driesen, Inorg. Chem., 2009, 48, 3018-3026.

72 S. Akerboom, M. S. Meijer, M. A. Siegler, W. T. Fu and E.

$80 \quad$ Bouwman, J. Lumin., 2014, 145, 278-282.

73 A. Mech, Polyhedron, 2008, 27, 393-405.

74 F. Pointillart, O. Maury, Y. Le Gal, S. p. Golhen, O. Cador and L. n. Ouahab, Inorg. Chem., 2009, 48, 7421-7429.

75 C. Merkens and U. Englert, Dalton Trans., 2012, 41, 4664-4673.

${ }_{85} 76$ J. A. Vicente, A. Mlonka, H. Q. N. Gunaratne, M. Swadzba-Kwasny and P. Nockemann, Chem. Commun., 2012, 48, 6115-6117.

77 T. Vander Hoogerstraete, S. Jamar, S. Wellens and K. Binnemans, Anal. Chem., 2014, 86, 3931-3938.

78 A. Stojanovic and B. K. Keppler, Sep. Sci. Technol., 2011, 47, 189-

$90 \quad 203$.

79 I. Billard, A. Ouadi and C. Gaillard, Dalton Trans., 2013, 42, 62036212.

80 X. Sun, H. Luo and S. Dai, Chem. Rev., 2011, 112, 2100-2128.

81 M. Ellinger, H. Duschner and K. Starke, J. Inorg. Nucl. Chem., 1978,

95 40, 1063-1067.

82 D. A. Johnson, A. B. Waugh, T. W. Hambley and J. C. Taylor, J. Fluor. Chem., 1985, 27, 371-378.

83 M. G. Freire, P. J. Carvalho, A. M. S. Silva, L. M. N. B. Santos, L. P. N. Rebelo, I. M. Marrucho and J. A. P. Coutinho, J. Phys. Chem.

$100 \quad B, 2009, \mathbf{1 1 3}, 202-211$.

84 M. G. Freire, C. M. S. S. Neves, P. J. Carvalho, R. L. Gardas, A. M. Fernandes, I. M. Marrucho, L. M. N. B. Santos and J. A. P. Coutinho, J. Phys. Chem. B, 2007, 111, 13082-13089.

85 L. I. N. Tomé, F. R. Varanda, M. G. Freire, I. M. Marrucho and J. A. P. Coutinho, J. Phys. Chem. B, 2009, 113, 2815-2825. 